\title{
Les jeux américains : une perspective historique
}

American Games: A historical perspective

\section{Bruce Whitehill}

Traducteur : Vincent Berry

\section{(2) OpenEdition \\ Journals}

\section{Édition électronique}

URL : http://journals.openedition.org/sdj/2964

DOI : $10.4000 /$ sdj.2964

ISSN : 2269-2657

\section{Éditeur}

Laboratoire EXPERICE - Centre de Recherche Interuniversitaire Expérience Ressources Culturelles Education

\section{Référence électronique}

Bruce Whitehill, «Les jeux américains : une perspective historique », Sciences du jeu [En ligne], 14 | 2021, mis en ligne le 20 mars 2021, consulté le 06 avril 2021. URL : http://journals.openedition.org/ sdj/2964; DOI : https://doi.org/10.4000/sdj.2964

Ce document a été généré automatiquement le 6 avril 2021.

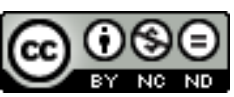

La revue Sciences du jeu est mise à disposition selon les termes de la Licence Creative Commons Attribution - Pas d'Utilisation Commerciale - Pas de Modification 4.0 International. 


\title{
Les jeux américains : une perspective historique
}

\author{
American Games: A historical perspective
}

\author{
Bruce Whitehill
}

Traduction : Vincent Berry

\section{NOTE DE L'ÉDITEUR}

Ce texte est une traduction intégrale par Vincent Berry de l'article de Bruce Whitehill (1999), « American Games : A Historical Perspective », Board Game Studies, 2, 116-141. Quelques corrections, mineures, ont été apportées par l'auteur à cette occasion. Sur sa proposition des illustrations ont été modifiées et ajoutées. Pour des raisons de mise en page et de lisibilité, nous avons renvoyé certaines incises de l'auteur, originalement entre parenthèses, en note. Nous avons également modifié les résumés de la publication originale.

1 Les historiens qui se sont consacrés à l'étude des jeux de plateau ont généralement porté leur attention sur les jeux anciens, antiques pour partie, sur la base de vestiges, de traces et de textes disponibles. À travers ces objets, il s'est agi le plus souvent de mieux connaître les sociétés dans lesquelles ces jeux ont été pratiqués, mais aussi de comprendre la façon dont ils ont circulé d'un territoire à l'autre (par les routes commerciales notamment) et leurs évolutions dans différentes cultures. Des titres classiques tels que les Echecs, les Dames, le Mancala, le Pachisi, le Moulin et le Jeu de l'Oie ont été étudiés en détail par de nombreux chercheurs (Falkner, 1961; Finkel, 1996; Murray, 1952). Beaucoup étaient joués sur des planches de bois finement sculptées et ne concernaient souvent que quelques privilégiés. Au milieu du $19^{e}$ siècle, les progrès de la lithographie et des techniques d'impression ont permis de produire des jeux en grandes quantités à des fins commerciales. Suffisamment bon marché pour être accessibles aux moins fortunés, ils ont pu atteindre un public plus large au point de devenir un objet ordinaire dans un nombre croissant de foyers. On ne sait 
paradoxalement que peu de choses sur cette période. Comment étaient utilisés ces jeux ? Étaient-ils conçus à des fins récréatives ou comme des instruments éducatifs ou pédagogiques? Qui fabriquait et diffusait ces jeux auprès du public?

Faire une histoire des jeux de société aux États-Unis présente une première difficulté : le terme « ancien » ne s'applique en effet guère dans un pays qui n'a été officiellement « découvert » qu'en 1492. Avant le $19^{e}$ siècle, l'essentiel des jeux joués par les colons est d'origine européenne. Stewart Culin (1992 [1907]) mentionne quelques titres pratiqués par les Premières Nations, mais il les regroupe sous la rubrique "jeux européens". Cependant, nombre d'entre eux, notamment ceux utilisant des dés, se révèlent en réalité des jeux autochtones. Méritant une étude spécifique, les jeux des Premières Nations n'ont pas ou peu été commercialisés et ne seront donc pas inclus dans le présent article consacré à l'émergence de l'industrie.

3 À partir des années 1860, on assiste aux États-Unis à l'apparition de petits éditeurs qui commencent à produire, à diffuser et à vendre des jeux. Fabricant le plus souvent artisanalement et en nombre limité des exemplaires diffusés localement, ces premières productions vont conduire en l'espace trente ans au développement d'une industrie florissante. Peu d'études ont été menées sur ce secteur et ses titres. Dans son index des jeux classés selon le pays d'apparition, Murray (1952) n'énumère que trois variantes de jeux originaires des États-Unis : Tit-Tac-Toe (une variante du morpion), Acey-deucey (une variante du Backgammon) et Chuba, une variante du Mancala. Il n'attribue d'ailleurs pas une origine américaine au jeu Halma qu'il recense, ce qui est pourtant le cas, nous y reviendrons. Vieille de près d'un siècle au moment de ses recherches, on peut supposer que Murray considérait vraisemblablement l'industrie nord-américaine du jeu de société comme trop "récente ", ou bien encore qu'il ne s'intéressait guère aux jeux « propriétaires » - ceux dont les droits appartiennent à une société particulière - bien que le jeu Chuba, qu'il évoque, ait été exclusivement publié par l'éditeur américain Milton Bradley (M.B.).

4 En étudiant les entreprises qui les ont produits et leurs contextes de diffusion, cet article s'attache à fournir les bases d'une histoire des jeux fabriqués aux États-Unis. Comme leurs ancêtres traditionnels (Bell 1980), ils sont le reflet de la culture dans laquelle ils sont fabriqués, et l'examen de certains d'entre eux permet d'éclairer les valeurs que leur attribuaient celles et ceux qui les ont achetés et pratiqués. Tout comme l'étude des objets ludiques anciens révèle quelque chose des cultures dans lesquelles ils ont été trouvés, les jeux de l'industrie de masse nous renseignent tout autant sur les valeurs et les comportements de l'époque. Pour ce faire, différentes méthodes de recherche ont été mobilisées pour constituer, pendant près de deux décennies, les matériaux qui donnent corps à cet article. Si la littérature ne nous renseigne guère sur l'histoire des jeux américains récents, les premiers catalogues de jeux d'entreprises et les nécrologies des principales figures de l'industrie se révèlent des ressources précieuses. Les comptes-rendus de journaux et les articles de magazines spécialisés fournissent également des informations et des données de première ou de seconde main.

5 Si les ouvrages pionniers dans le domaine des études sur le jeu, particulièrement ceux de Stewart Culin (1992, [1907]), d'Edward Falkener (1961) et d'Harold Murray (1962) ont contribué à définir le cadre d'une histoire générale des pratiques ludiques, des auteurs plus récents tels que Ralph Anspach (1998), Richard Levy et Ronald Weingartner (1990), Philip Orbanes (1998), Steven Peek (1987) et Anne Williams (1990) fournissent des 
informations plus précises sur l'industrie américaine contemporaine. Les livres magnifiquement illustrés de Richard Bell (1979a, 1979b, 1980) et de Brian Love (1979a, 1979b) ont été une source d'inspiration. L'analyse du magazine professionnel Playthings ${ }^{1}$ s'est de même révélée être une importante ressource, tout comme les annuaires de l'American International Toy Fair', les brochures promotionnelles de Parker Brothers ainsi que la biographie de Milton Bradley par James J. Shea (1973). L'étude des brevets de jeux et des premières publicités imprimées a été tout aussi éclairante. Mais, ce qui s'est révélé peut-être le plus important pour notre enquête, c'est l'analyse des objets, les jeux de société eux-mêmes, que le monde des collectionneurs (dont je fais partie ${ }^{3}$ ) a conservés, et qui permettent, de façon comparée et longitudinale, de mieux comprendre les conditions et les contextes de fabrication et de diffusion. Précisons enfin que quelques données sur l'évolution de l'industrie, dans ses aspects anecdotiques, mais aussi techniques, ont été recueillies pendant plusieurs années, au sein même des bâtiments dans lesquels certains de ces jeux ont été conçus, fabriqués et commercialisés ${ }^{4}$. Les connaissances acquises grâce à des entretiens avec des inventeurs de jeux, des responsables de vente, des présidents de sociétés de jeux et divers acteurs de l'industrie (les fondateurs ou leurs descendants) ont été essentielles pour mettre en perspective toutes les données accumulées.

\section{Avant la production de masse}

6 Pendant longtemps, les plateaux de jeu (tout au moins ceux dont nous avons des traces) ont été sculptés dans le bois, gravés, dessinés sur la pierre et l'ardoise ou même tissés en osiers. Nous savons que certains d'entre eux ont été pratiqués dans les civilisations anciennes de la Mésopotamie, de la vallée de l'Indus et de l'Égypte, il y a 5000 ans et peut-être même plus. Des plateaux, comme celui du Senat, ont été découverts en 1922 dans la tombe de Toutankhamon où ils étaient enterrés depuis plus de 3200 ans. Certains de ces jeux anciens semblent n'avoir été diffusés que dans la région où ils ont été introduits ou à proximité tandis que d'autres, encore pratiqués aujourd'hui, ont circulé dans le monde entier. Il est difficile à ce jour d'identifier les premières dates et les pays d'origine des jeux anciens. Ils ont évolué au fil des siècles et parfois le successeur ne ressemble guère à son ancêtre. À la recherche de leurs origines, de nombreux historiens s'attachent toujours à étudier les structures, les mécaniques de jeux et leur filiation.

7 Tout un ensemble de jeux traditionnels se joue dans le monde entier depuis des générations, sous une forme ou une autre: appelées drafts en Angleterre, les Dames, remontent au $12^{\mathrm{e}}$ siècle - on y joue dans certaines régions du monde sur un plateau de huit cases par huit et dans d'autres sur un plateau de dix par dix. Si les origines des Echecs sont toujours discutées, la Chine, l'Inde et la Perse restent à ce jour les trois lieux probables de naissance, quelque part entre 500 avant et 500 ans après l'ère chrétienne. Selon Ulrich Schädler (1995), le backgammon a succédé à un jeu qui remonte au moins au $1^{\text {er }}$ siècle avant J.C., appelé 12 lignes, et plus tard Alea (une variante a été trouvée en Islande sous le nom plus récent de Chasse aux filles). Parmi ces jeux européens qui ont été pratiqués aux États-Unis, il faut évoquer le Jeu du renard et de l'oie, qui voit le jour vers 1300 peut-être en Islande, ainsi que le Jeu de l'oie, qui apparait en Europe vers le $16^{\mathrm{e}}$ siècle et dont le plus ancien produit aux États-Unis fut imprimé en 1851. 
8 L'origine de beaucoup de jeux traditionnels remonte à l'Afrique et à l'Orient. Populaire dans le monde entier depuis des siècles, l'une des plus anciennes planches du Moulin, aussi connu sous le nom de Nine Men's Morris ou de Marelle, a été trouvée en Égypte. Le Go, un jeu ancien de Chine devenu au cours du temps un jeu national du Japon, a gagné un nombre croissant d'adeptes aux États-Unis. Le Mah Jong, avant de connaitre un important succès aux États-Unis au début des années 1920, fut l'un des jeux les plus pratiqués en Chine pendant une grande partie du $19^{\mathrm{e}}$ siècle. Le Pachisi, également pratiqué aux États-Unis, est vieux de plusieurs siècles, bien que sa date d'apparition soit encore objet de débat. Milton Bradley et l'éditeur McLoughlin en ont produit une version américaine au tournant du $19^{\mathrm{e}}$ siècle sous le nom de Game of India et de Royal Game of India ${ }^{5}$ tandis qu'en 1896, une version similaire était jouée en Angleterre sous le nom de Ludo ${ }^{6}$.

Dans l'histoire des jeux, les routes commerciales ont contribué à la diffusion de certains titres dans le monde. Les biens personnels ou les souvenirs des voyageurs pouvaient contribuer à établir un jeu dans une nouvelle culture. La plupart des premiers jeux qui ont perduré et qui ont été transportés dans différents territoires étaient souvent de type stratégique, mettant au cœur de la partie une confrontation (sans heurts) au terme de laquelle un joueur doit vaincre son adversaire. Ces jeux de stratégie pure supposaient souvent la capture des pièces de l'adversaire, l'alignement de ses propres pions, ou encore l'emprisonnement de ceux de son adversaire. Ces types de pratiques furent souvent perçus dans leur histoire comme une forme d'exercice intellectuel - les activités et les passe-temps nécessitant habileté physique et motricité renvoyant plus directement au domaine du sport.

10 La révolution industrielle, qui commence vers 1760 en Angleterre et plus tardivement dans d'autres pays, voit les machines prendre en charge une partie du travail manuel et le temps libre des travailleurs s'accroitre. Les premiers jeux de société sont alors imprimés sur du papier, parfois recouvert de lin, et vendus à ceux qui en avaient les moyens financiers, mais aussi la disponibilité. Juste après le milieu du $19^{\mathrm{e}}$ siècle, les progrès réalisés dans le domaine des techniques d'impression permettent une augmentation de la production d'exemplaires à un prix moindre, les rendant ainsi plus accessibles encore. À la fin du $19^{\mathrm{e}}$ siècle, qu'il s'agisse de cartes ou de plateaux, les jeux de société s'inscrivent progressivement dans le quotidien des travailleurs et contribuent à dessiner les nouvelles formes et styles de vie familiaux et urbains aux États-Unis et en Europe.

\section{Les premiers jeux américains}

11 À ses débuts, l'édition de jeux de société aux États-Unis est un secteur très marginal au regard de la situation européenne. Sans surprise, la plupart des premiers jeux fabriqués aux États-Unis sont des adaptations ou des importations de titres du vieux continent, en particulier de la Grande-Bretagne. Selon McClinton (1970), le journal américain The Pennsylvania Packet proposait dès 1775 des publicités pour des jeux de voyage, d'histoire et de géographie, vraisemblablement de fabrication britannique. Bien que quelques jeux de cartes soient fabriqués aux États-Unis dès la fin $\mathrm{du} 17^{\mathrm{e}}$ siècle, l'édition de jeux de plateaux ne se fera que beaucoup plus tard.

12 Comme les cartes et les planches de jeu étaient initialement imprimées sur du carton ou du papier par des lithographes et des imprimeurs, les jeux étaient considérés dans 
un premier temps comme relevant plutôt de la "publication » que de la «fabrication manufacturée ». À ce titre, les fabricants et les inventeurs de ces premiers jeux sont souvent crédités en tant qu'auteurs - ce qui est rare dans le cas des jeux américains contemporains. Il est possible que la notion de "publication» ait encouragé cette forme de reconnaissance. Par la suite, à mesure que les jeux de société sont considérés comme des "fabrications manufacturées", le nom de l'inventeur se perd progressivement dans la multitude d'artistes, de concepteurs, d'écrivains et d'ingénieurs qui participent à la création et à la mise sur le marché du produit.

Avant 1822, date à laquelle deux titres, Travelers' Tour Through the Unites States et Travelers' Tour Through Europe, sont publiés par l'éditeur new-yorkais F. \& R. Lockwood, aucun jeu de société commercial américain n'a été trouvé. L'absence d'importations anglaises liée à l'imposition de restrictions commerciales avec la Grande-Bretagne en 1809 a vraisemblablement encouragé des sociétés comme F. \& R. Lockwood à éditer leurs propres jeux. Il est toutefois étonnant qu'aucun autre titre n'ait été découvert pendant les deux décennies suivantes. Cependant, très peu de recherches ont été menées et l'on peut raisonnablement s'attendre à découvrir des titres produits et diffusés dans cette période sur une base au moins régionale.

Une vingtaine d'années plus tard, en 1843, une petite société d'édition du Massachusetts, W. \& S.B. Ives publie The Mansion of Happiness ${ }^{7}$ (figure 1). Il s'agit d'une copie directe de son homonyme anglais publié vers 1800 . Ce jeu vise à l'instruction morale de ses joueurs : ceux qui poursuivent le vice seront punis (renvoyés), et ceux qui font preuve de vertus admirables seront récompensés. Sur le plateau de jeu, imprimé sous le titre, un court texte précise qu'il s'agit d'un divertissement moral instructif et se voit agrémenté du poème suivant :

Dans ce divertissement, chacun trouvera

Un cadre moral qui l'esprit soutiendra ;

Il récompensera comme ils le méritent

Ceux qui s'engagent sur les voies du vice,

Et montrera que (si le vice est destructeur)

Toute vertu, du bien, en est la fleur

Soyez donc vertueux et toujours avancez,

Pour gagner le siège de la félicité.

Le déplacement sur le tablier, en forme de spirale, vers la maison du bonheur est régi par un toton. Lorsqu'un joueur atterrit sur une case indiquant une vertu, il progresse vers la maison du bonheur. Lorsqu'il finit son mouvement sur une case illustrant un vice, il doit revenir en arrière. Ainsi, un joueur sur la case numéro quatorze, intitulée «Passion », doit retourner à la case numéro six «L'Eau ». La règle précise : « Quiconque entre dans une Passion doit être emmené dans l'Eau et avoir un bein [sic] pour le refroidir. » Atterrir sur «l'Oisiveté » renvoie à la case « Pauvreté »; les joueurs sur le «Chemin de la Folie» retournent à la «Prudence»; la case «Parjure» mène au "Pilori» (un cadre en bois avec des trous pour la tête et les mains); le "Briseur de Sabbat » était "emmené en salle de torture et fouetté »; tout joueur qui atteignait le «Sommet de la Dispersion» (une forme de gaspillage) allait à la "Ruine». Le ton général du jeu pouvait ainsi se résumer à deux de ses règles :

Quiconque connait la piété, l'honnêteté, la tempérance, la gratitude, la prudence, la vérité, la chasteté, la sincérité, l'humilité, le labeur, la charité, l'humanité ou la générosité a le droit d'avancer... vers la maison de la félicité. 
Quiconque connait l'audace, la cruauté, l'immodestie ou l'ingratitude, doit retourner à sa situation antérieure... et ne même pas penser au bonheur, et encore moins y prendre part.

Figure 1: The Mansion of Happiness board (Ives, 1843)

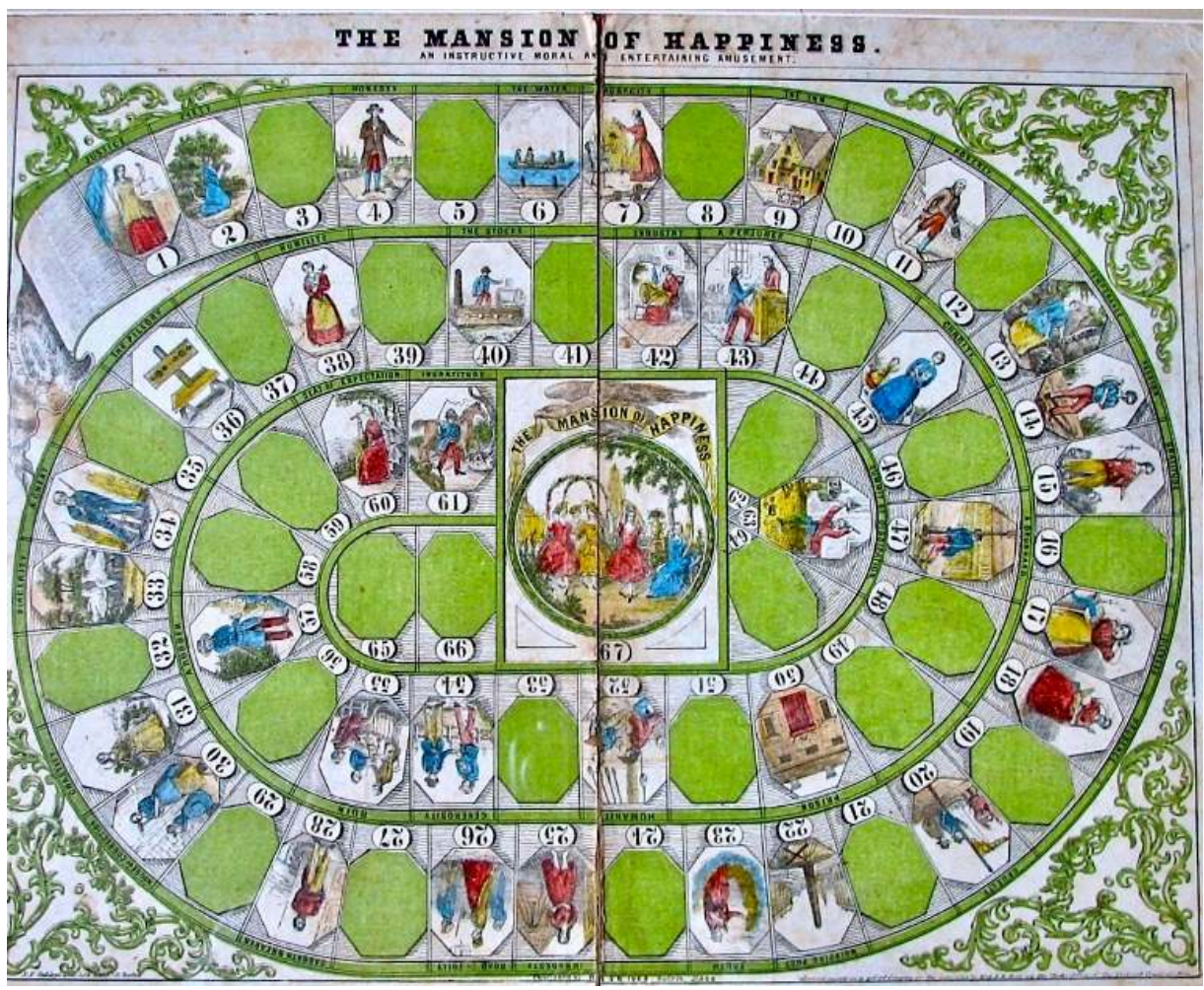

La ferveur morale de l'époque se reflète également dans d'autres jeux de l'éditeur dont les titres témoignent bien de la ligne éditoriale suivie: The Game of Pope or Pagan ${ }^{8}$, ou encore the Siege of the Stronghold of Satan by the Christian Army ${ }^{9}$, publié en 1844. Édité la même année, le jeu The National Game of the American Eagle ${ }^{10}$ ajoute à la volonté d'élever spirituellement ses joueurs des enseignements plus civiques, avec notamment cette étonnante règle: "Celui qui sacrifie ses principes en devenant fonctionnaire recule", tandis que « celui qui connait le désintéressement peut continuer».

17 Cette logique de progression en fonction des traits et des actions, bonnes ou mauvaises, des joueurs est au principe de nombreux jeux de société publiés à la fin $\mathrm{du} 19^{\mathrm{e}}$ siècle. On peut ainsi penser aux deux titres édités par McLoughlin Brothers en 1886 The Game of Messenger Boy ${ }^{11}$ et The Errand Boy ${ }^{12}$ (figure 2) dans lesquels il s'agit d'élever au rang de directeur d'une entreprise un jeune issu des milieux populaires. Cette mécanique se veut une illustration de l'expression "des haillons aux richesses ${ }^{13}$ promue alors par des auteurs à succès comme Horatio Alger, écrivain américain à la mode dans les années 1860. Dans des romans d'éducation adressés aux garçons, il mettait en scène des personnages qui, grâce à une vie exemplaire et après avoir surmonté différentes épreuves comme la pauvreté, s'élevaient et réussissaient socialement à force de travail et de vertu. 


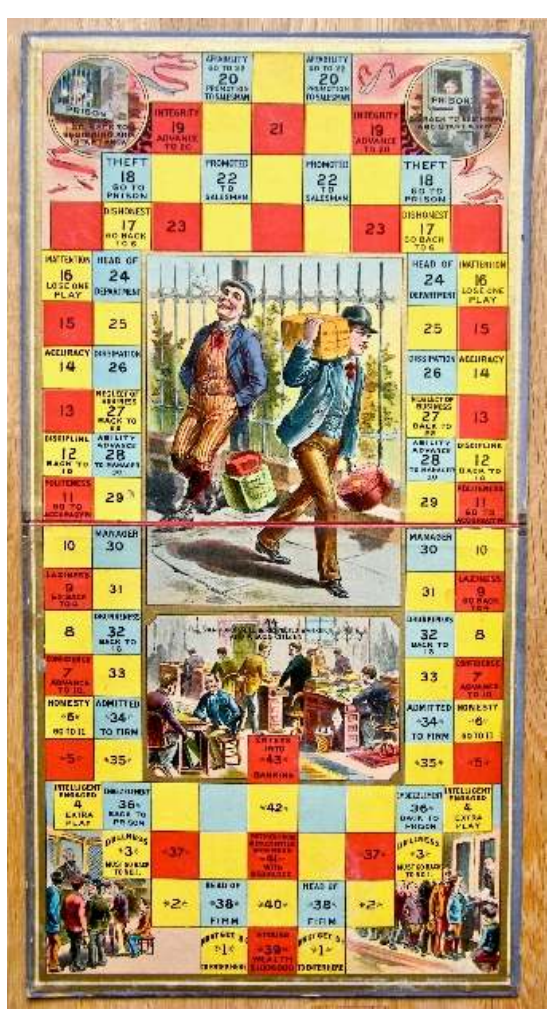

Durant cette période de ferveur religieuse et morale, le jeu est fréquemment condamné par la société bourgeoise. Souvent associés aux jeux de hasard, les dés étaient qualifiés d'« outils du diable». Pendant la guerre civile (1860-1864), les soldats en emmenaient parfois quelques-uns en dépit des discours puritains à leur égard. Mais ils les retiraient régulièrement de leurs poches avant d'aller au front, de sorte que, s'ils étaient tués au combat, ils ne fassent pas partie des effets personnels renvoyés à la famille. Les champs de bataille de la guerre de Sécession se sont ainsi révélés un endroit privilégié dans la découverte des premiers dés en os.

Pour éviter les stigmates liés aux dés, les premiers fabricants de jeux utilisent alors des totons, semblables aux toupies : les chiffres de 1 à 6 (ou de 1 à 8 ) sont imprimés sur un morceau de carton hexagonal (ou octogonal) et une tige en bois avec un bout pointu est enfichée au milieu du carton, créant ainsi un instrument équilibré que l'on peut faire tourner entre le pouce et l'index. Lorsque le toton cesse de tourbillonner, le nombre supérieur indique le nombre de cases (ou la direction) que le joueur est autorisé à suivre.

20 La société W. \& S.B. Ives, localisée à Salem dans le Massachusetts, est souvent considérée comme le premier fabricant de jeux de société aux États-Unis. Elle publie au moins deux douzaines de titres au milieu des années 1800 , dont le jeu de cartes à succès, Dr Busby (figure 3). The Mansion of Happiness qu'il édite en 1843 a longtemps été considéré comme le premier jeu de société américain. Lorsque Parker Brothers rachète l'éditeur en 1887 et réédite le titre en 1894, il est précisé sur le plateau de jeu qu'il s'agit du «premier jeu de société jamais publié en Amérique » (figure 4) - une déclaration dont on sait maintenant qu'elle est fausse. W. \& S.B. Ives est quasiment le seul éditeur américain jusqu'en 1850, date à laquelle l'éditeur de livre John McLoughlin commence à vendre des jeux de cartes colorées à la main. Ce dernier développe rapidement l'une 
des premières chaînes de montage aux États-Unis : différents artistes sont responsables d'une couleur, de sorte que les cartes passaient de l'un à l'autre jusqu'à ce que toutes les couleurs soient ajoutées. En 1858, McLoughlin crée la société McLoughlin Brothers et fabrique une série de jeux considérés comme parmi les plus belles productions jamais publiées aux États-Unis. L'éditeur connait son apogée dans les années 1880 et se restera un acteur majeur du secteur jusqu'à ce son rachat par M.B. en 1920.

Figure 3 : Dr Busby « Le plus vieux jeu américain » (Parker Bros, 1890)

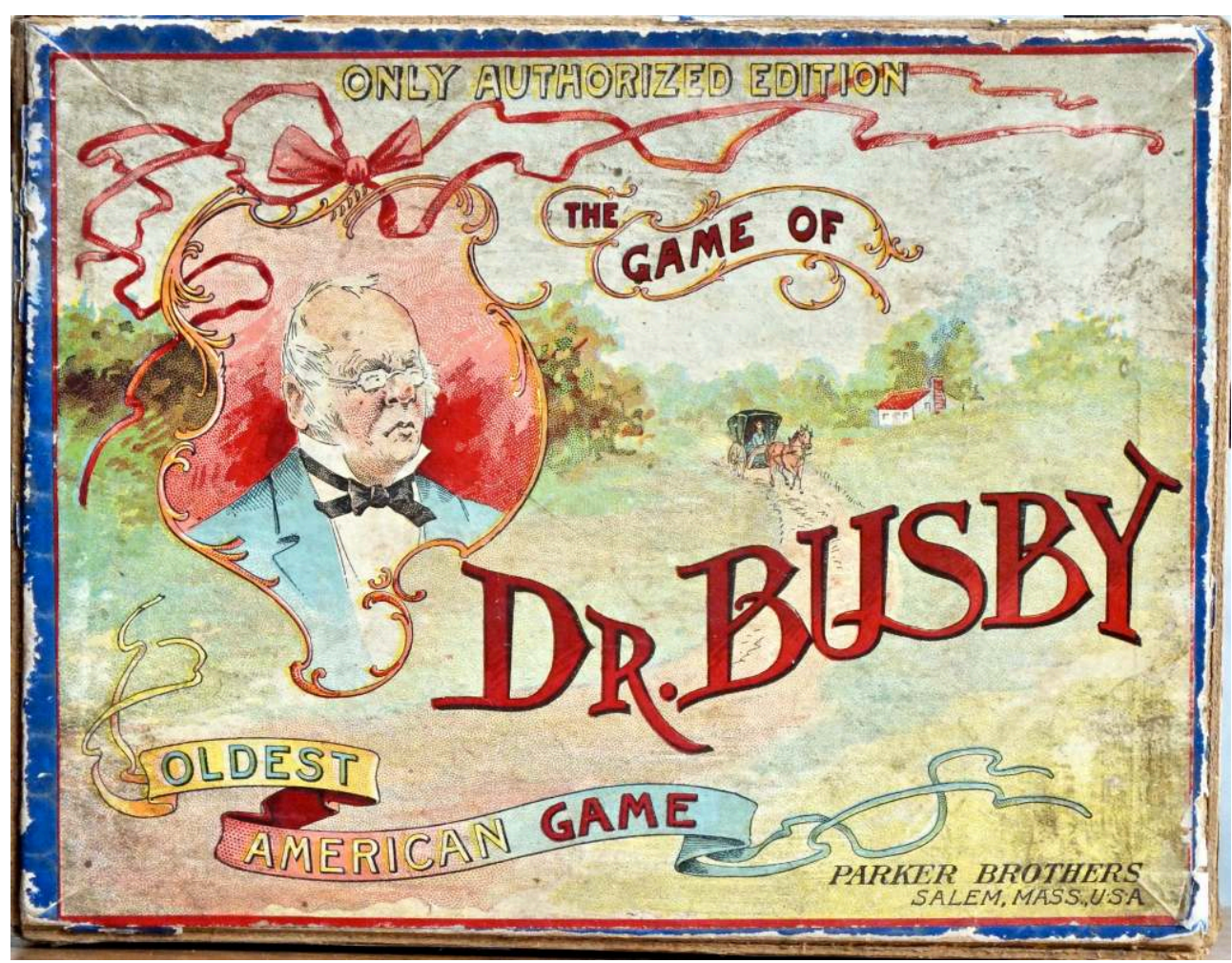


Figure 4 : The Mansion of Happiness, " le Premier jeu de plateau jamais publié en Amérique", réédition, (Parker Bros, 1894)

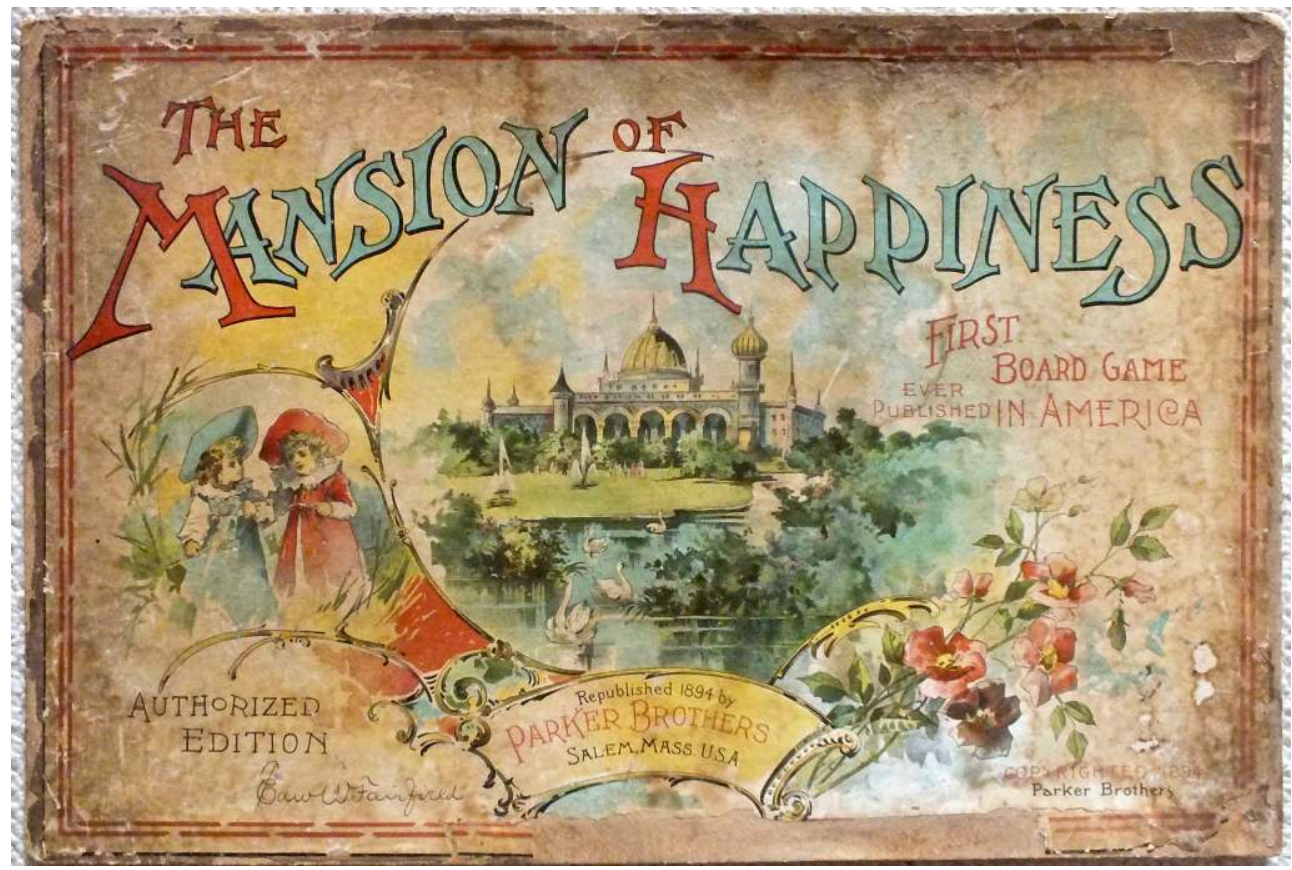

\section{Le début de l'industrie américaine}

21 L'industrie américaine du jeu ne se développe véritablement en tant que telle qu'en 1860, lorsque Milton Bradley, un lithographe, apporte d'importantes améliorations au processus d'impression qui permet la production en masse d'images en couleur. Son premier jeu, The Checkered Game of Life (figure 5), est, comme beaucoup d'autres à l'époque, un jeu à vocation "morale ", conçu sous la forme d'un chemin qui mène le joueur de l'enfance à la vieillesse heureuse. Si le magazine Playthings le qualifie quelques années plus tard de "premier jeu ayant un but (qui) vous apprend à mener une vie juste et intègre », de nombreux titres, nous l'avons vu, avaient préalablement développé cette logique. The Checkered Game of Life utilise également un toton pour déterminer si un joueur peut se déplacer d'une ou deux cases vers la gauche, vers la droite ou en diagonale. De nombreuses cases indiquent un trait de caractère et une conséquence. Atterrir sur la case "Bravoure» envoie ainsi le joueur sur celle de «l'Honneur », la « Persévérance » sur « le succès » et «l'Ambition » vers la « Gloire ». La case «jeu de hasard » conduit à la «Ruine » et l' » Oisiveté » à la « Disgrâce ». Ce succès de Milton Bradley se voit renforcé par le développement de ce que l'on pourrait considérer comme les premiers "jeux de voyage»: des versions réduites de The Checkered Game of Life sont conçues pour tenir dans la poche ou le sac à dos des soldats pendant la guerre civile. 
Figure 5: The Checkered Game of Life (Milton Bradley, 1860)

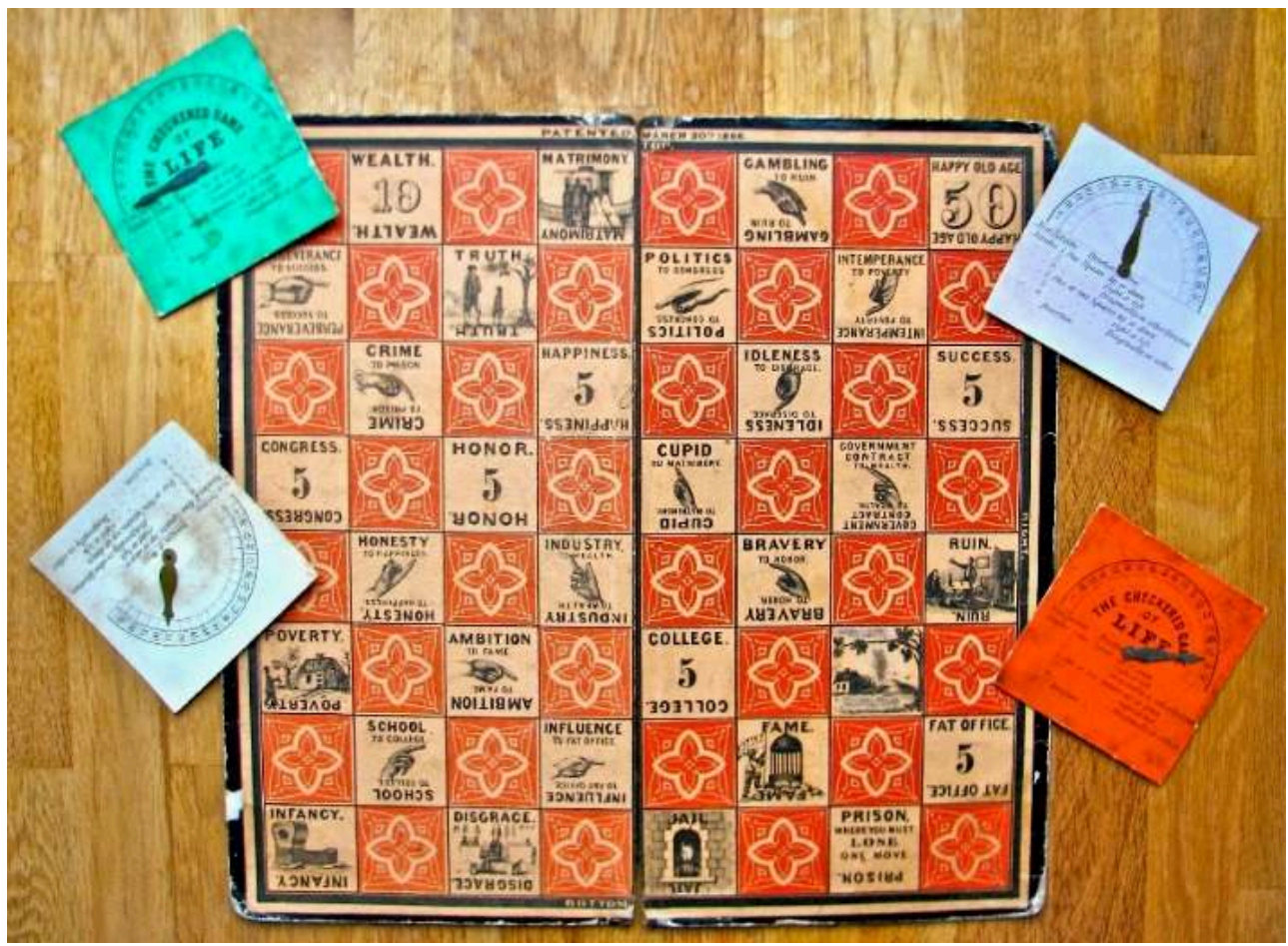

En 1860, plusieurs innovations en matière d'impression permettent la production de jeux en masse et le travail manuel du coloriste disparait progressivement. À cette période, les plateaux sont réalisés en collant une feuille de lithographie colorée sur un morceau de carton. Fait remarquable, le format de planche de 18" x 18 " utilisé dans les années 1870 est le même que celui aujourd'hui employé pour la plupart des planches de jeu, comme dans le jeu Bamboozle de Milton Bradley en 1876 par exemple (figure 6). On perçoit ici un début standardisation de l'industrie dans l'impression et la fabrication des plateaux. 
Figure 6 : Bamboozle (Milton Bradley, 1876)

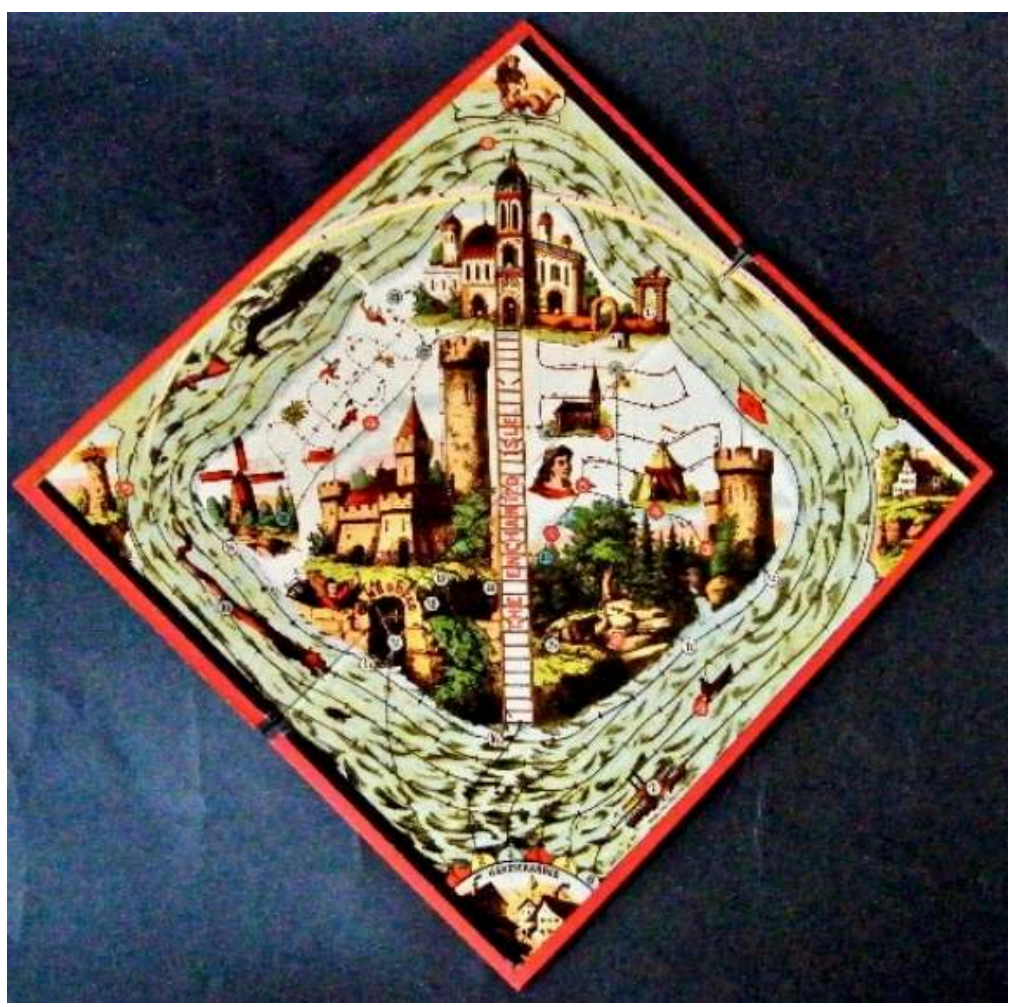

Milton Bradley se révèle actif dans différents domaines. Il brevète le premier jeu de croquet aux États-Unis en 1866 et en établit les règles. Il introduit le Zootrope (machine à images animées) aux États-Unis, fabrique des coupe-papiers et vend également des copies de portraits d'Abraham Lincoln (alors sans barbe - aujourd'hui très recherchées dans le monde des collectionneurs). Au cours de la grande déflation de 1879, M.B. suit de près l'évolution du monde de l'éducation et produit, en plus des jeux, des fournitures scolaires et des jouets optiques pour les jeunes et leurs familles. Selon James J. Shea (1973), l'entrepreneur s'est personnellement investi dans la fabrication et l'expérimentation de matériel en vue du développement d'un système universel de jardins d'enfants. Perdant de l'argent à ses débuts, l'activité de la société dans le domaine du matériel éducatif devient peu à peu rentable et dominante sur le marché. L'entreprise est l'une des plus florissantes et possède en 1900 plusieurs bureaux à New York, au Kansas, à Atlanta, à San Francisco et à Philadelphie.

Encouragées par le succès de M.B., d'autres sociétés de jeux de société vont progressivement voir le jour dans cette période. En 1867, Elisha Selchow prend la direction d'une entreprise de vente de jouets à New York et vend trois ans plus tard l'un des jeux les plus populaires de l'époque, Pigs in Clover, un casse-tête qui mêle réflexion et adresse. Sa société, E.G. Selchow \& Co. qui devient par la suite Selchow \& Righter, est d'abord un distributeur. Leur catalogue de 1877 comprend 149 jeux et puzzles de M.B. et 45 jeux et pièces de McLoughlin ${ }^{14}$. À partir de 1927, la société édite sa propre gamme de jeux sous l'impulsion de la présidente Harriet T. Righter, qui prend la direction de l'entreprise en 1923, quelques années après la mort de son père John Righter et d'Elisha Selchow. Contrairement à d'autres comme M.B., le nom de cet éditeur reste aujourd'hui encore peu connu aux États-Unis malgré non seulement une histoire longue de 119 ans, mais aussi la publication de trois jeux particulièrement 
célèbres : le Trivial Pursuit, introduit sur le marché américain en 1984 depuis le Canada, le Scrabble, commercialisé en masse pour la première fois en 1953 et qui reste aujourd'hui le premier jeu de lettres mondial, ainsi que le Parcheesi. Ce dernier, basé sur le jeu indien Pachisi, fait l'objet d'un dépôt de marque en 1874 - l'une des plus anciennes pour un jeu américain.

Si la grande déflation des années 1870 ralentit le secteur, de nouveaux entrants apparaissent néanmoins. Alimentant une passion pour l'invention de jeux, George S. Parker développe en 1883 une société en son nom propre. Cinq ans plus tard, un de ses frères rejoint la société et Parker Brothers est créé. En 1894, le catalogue de l'éditeur précise que leur « nouvelle usine [à Salem, Massachusetts] est le seul grand bâtiment en Amérique consacré exclusivement aux jeux de société ». Alors que les jeux de Milton Bradley s'adressent principalement aux enfants et à la famille, Parker Bros oriente un certain nombre de ses produits vers les adultes.

A côté des jeux à vocation morale de l'époque, les premières productions américaines sont des jeux de stratégie qui, comme les jeux traditionnels, supposent des manœuvres tactiques étroitement associées à la guerre, le but étant de déjouer un adversaire, de piéger ses pièces ou de les retirer du jeu. Ainsi, parmi les premiers jeux fabriqués aux États-Unis, beaucoup sont des adaptations de titres venus d'Angleterre, d'Europe et d'Asie, au rang desquels le jeu du Renard et des Oies, le Mancala et, bien sûr, les Dames, les Echecs et le Backgammon. Un seul jeu de stratégie de cette fin du $19^{\mathrm{e}}$ siècle est une création originale, inventée aux États-Unis: Halma (figure 7), encore joué dans le monde entier - mais paradoxalement peu ou pas dans son pays d'origine.

Figure 7 : Halma (Horsman, 1885, 1888)

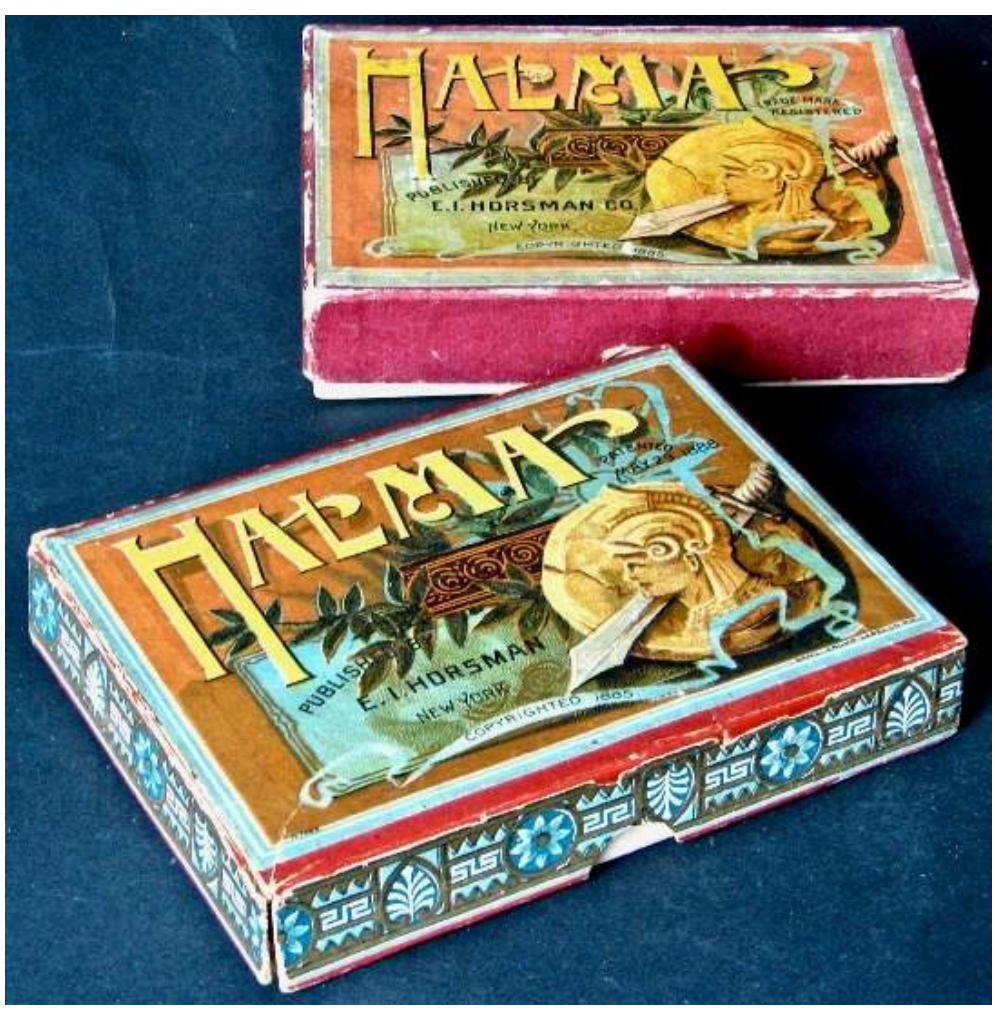

Considéré à tort par certains auteurs comme un jeu anglais, Halma, précurseur des Dames Chinoises, a été en effet inventé en 1885 par George Howard Monks. La confusion 
tient à ce que ce dernier avait de la famille en Angleterre qu'il visitait fréquemment et où le jeu se diffuse également. Né aux États-Unis, c'est dans le Massachusetts que Monks développe son prototype qui sera fabriqué et diffusé dans un premier temps en 1885 par E.I. Horsman (une société plus connue pour ses poupées que pour ses jeux), puis, pendant une courte période, par Milton Bradley. Les deux entreprises se lanceront par ailleurs dans une bataille juridique au terme de laquelle M.B. abandonnera l'édition du titre pour éditer un jeu similaire, sous le titre Eckha, tiré de l'allemand «Ecke », qui signifie "coin", en raison du positionnement des "troupes" de chaque joueur qui, placées dans un bord du plateau en début de partie, doivent pour l'emporter occuper le coin opposé. E.I. Horsman est donc resté longtemps le principal éditeur du titre, se faisant parfois appeler "The Halma Company». En Angleterre, un équivalent britannique est commercialisé sous le nom de Hoppity.

Jusqu'aux grandes vagues migratoires des années 1880 qui vont progressivement transformer la société américaine, la valeur sociale associée au temps libre n'a pas beaucoup évolué depuis l'époque coloniale. Comme représentée dans The Checkered Game of Life de Milton Bradley, l'oisiveté est considérée comme menant au déshonneur. Dans cette période, l'enfance et la jeunesse sont, plus qu'aujourd'hui, prises dans un ensemble de tâches et de responsabilités qu'il s'agisse de travaux agricoles, en magasin ou en usine. Les divertissements sont bien sûr autorisés, mais on attend des jeux qu'ils soient instructifs et éducatifs. Une grande partie des titres du $19^{\mathrm{e}}$ siècle portent ainsi sur l'histoire et la géographie et se présentent fréquemment sous la forme d'un jeu de questions/réponses. Le jeu de cartes le plus populaire de l'époque est Authors (figure 8), de type « 7 familles", sur le thème des grands écrivains. La valeur et la place sociale accordée à la famille sont importantes de sorte que la plupart des jeux sont conçus pour être joués par les parents et les enfants comme en témoignent de nombreuses illustrations des couvercles des premières boîtes de jeu montrant souvent trois générations, hommes et femmes, en train de jouer (figure 9). On comprend que la dimension de convivialité familiale est aussi importante que sa valeur éducative ou divertissante. 
Figure 8 : Vignette Authors, (E.G. Selchow, 1874)

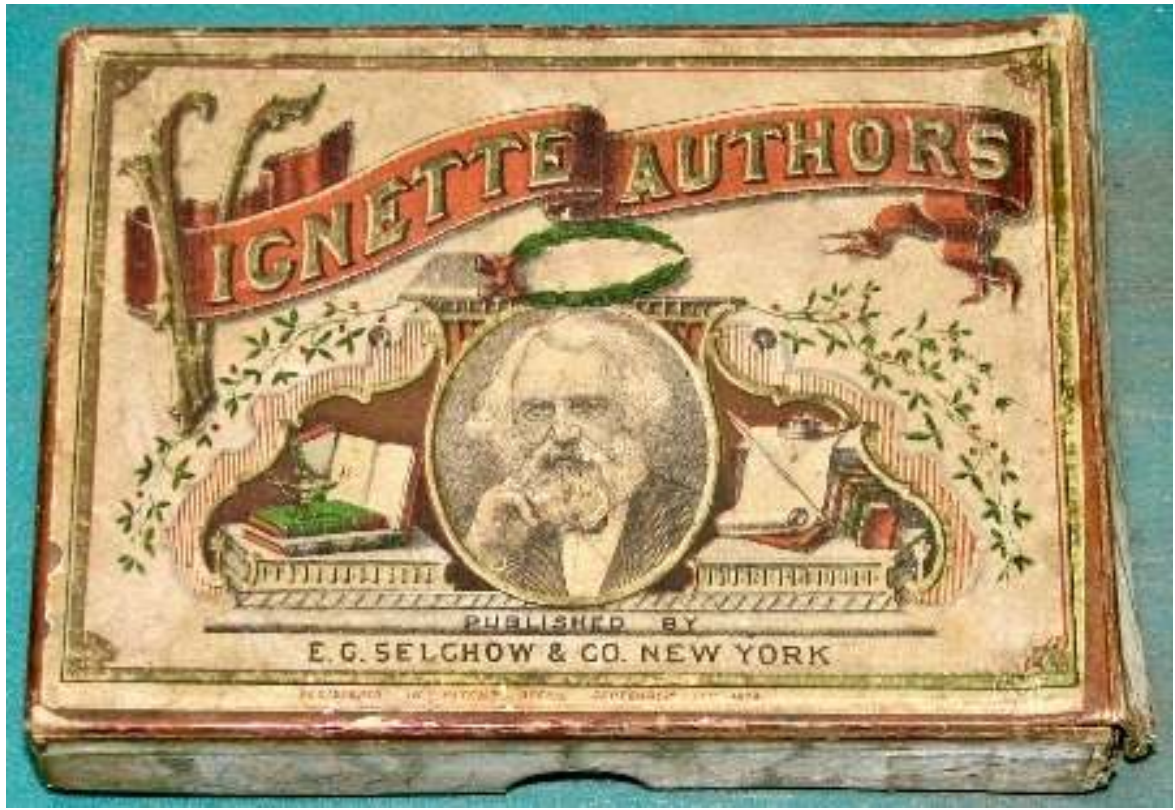

Figure 9 : Publicité 1898

Image 100BF2580000331B0000485A938ABF23B3813B11.emf

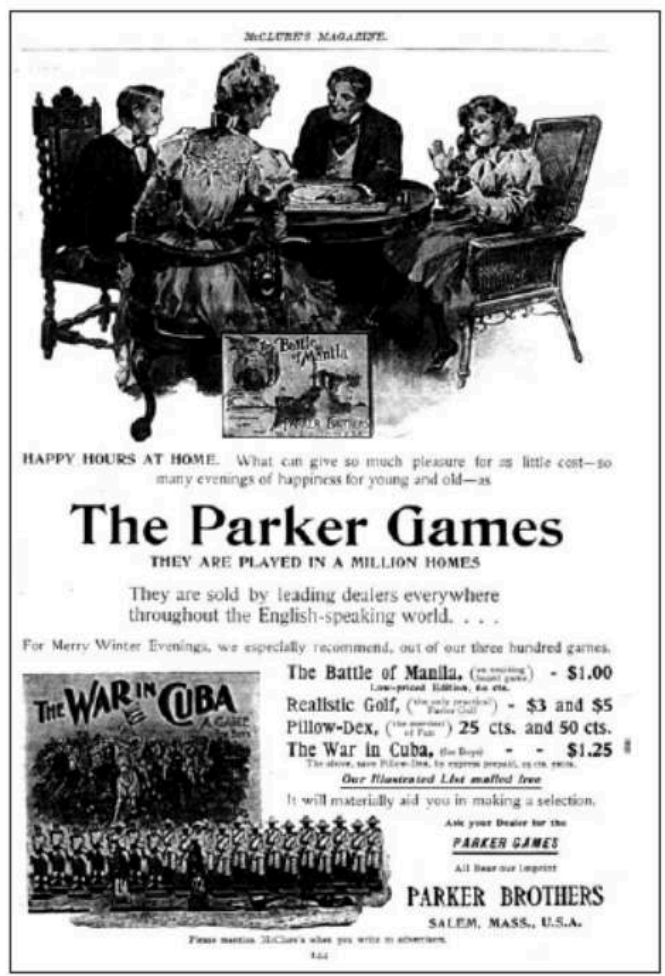

À la fin du $19^{\mathrm{e}}$ siècle, devant la multiplication des éditeurs, la production de jeux aux États-Unis devient un secteur industriel identifiable et spécifique. Il est principalement localisé dans le Nord-Est: le Massachusetts et la région métropolitaine de New York. Une société notable, R. Bliss, s'établit à Rhode Island. La Pennsylvanie regroupe quelques sociétés de jeux, tout comme, dans une moindre mesure, l'Ohio et l'Illinois. Au 
sortir de la déflation des années 1870, des sociétés comme McLoughlin, Parker Brothers, Milton Bradley et J.H. Singer produisent des jeux de grande qualité avec une lithographie exceptionnelle : certains présentent des boîtes en bois et incorporent des dés en os, des jetons en métal et des pièces de jeu sculptées sur un tour à bois. Si de nombreuses sociétés liées au jeu de plateau sont présentes, McLoughlin, Milton Bradley, E.G. Selchow et Parker Bros dominent rapidement le marché. De façon isolée dans un premier temps, ces dernières vont progressivement structurer le secteur du jeu de société tel qu'on le connait aujourd'hui et des premières concentrations d'entreprises ont lieu. À la fin des années 1880, Parker Bros obtient ainsi les droits sur le catalogue de jeux d'Ives et, en 1920, McLoughlin est racheté par M.B. Ce dernier, avec E.G. Selchow et Parker Brothers, resteront des entreprises familiales et indépendantes jusqu'à la seconde moitié du $20^{\mathrm{e}}$ siècle.

Les jeux produits aux États-Unis en cette fin de siècle reflètent un ensemble d'événements et changements de la période à l'échelle nationale et internationale. L'achèvement du chemin de fer transcontinental donne lieu à de nombreux jeux sur le thème $d u$ train. Les vélocipèdes sont représentés sur les boîtes jusqu'à ce que les bicyclettes ne les remplacent. Le célèbre pont de Brooklyn fait son apparition peu après son achèvement. Les gratte-ciels deviennent des illustrations fréquentes tout comme la Statue de la Liberté après avoir quitté la France pour New York. Le tramway apparait sur d'innombrables boîtes de jeu peu de temps après que le chemin de fer électrique ne débute en Virginie. La course autour du monde de Nellie Bly (battant les fictifs 80 jours de Phileas Fogg) est l'objet d'un magnifique jeu de McLoughlin (figure 10).

Figure 10: Round the World with Nellie Bly (McLoughlin, 1890)

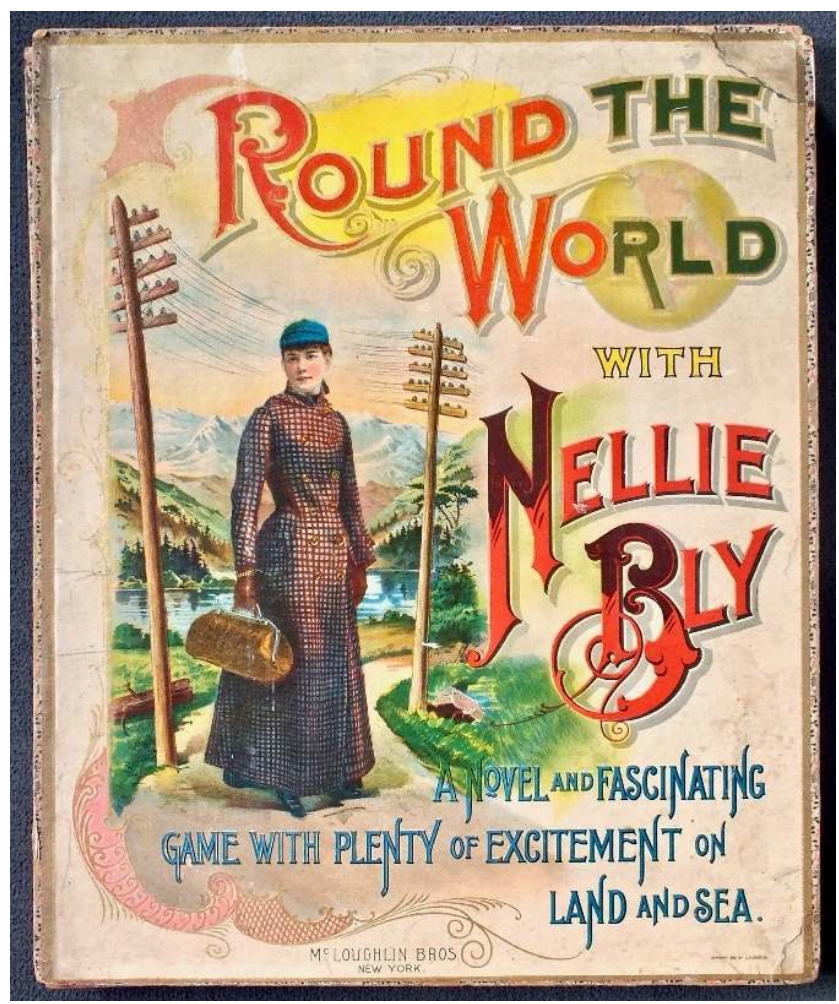


Figure 10 bis: Round the World with Nellie Bly (McLoughlin, 1890)

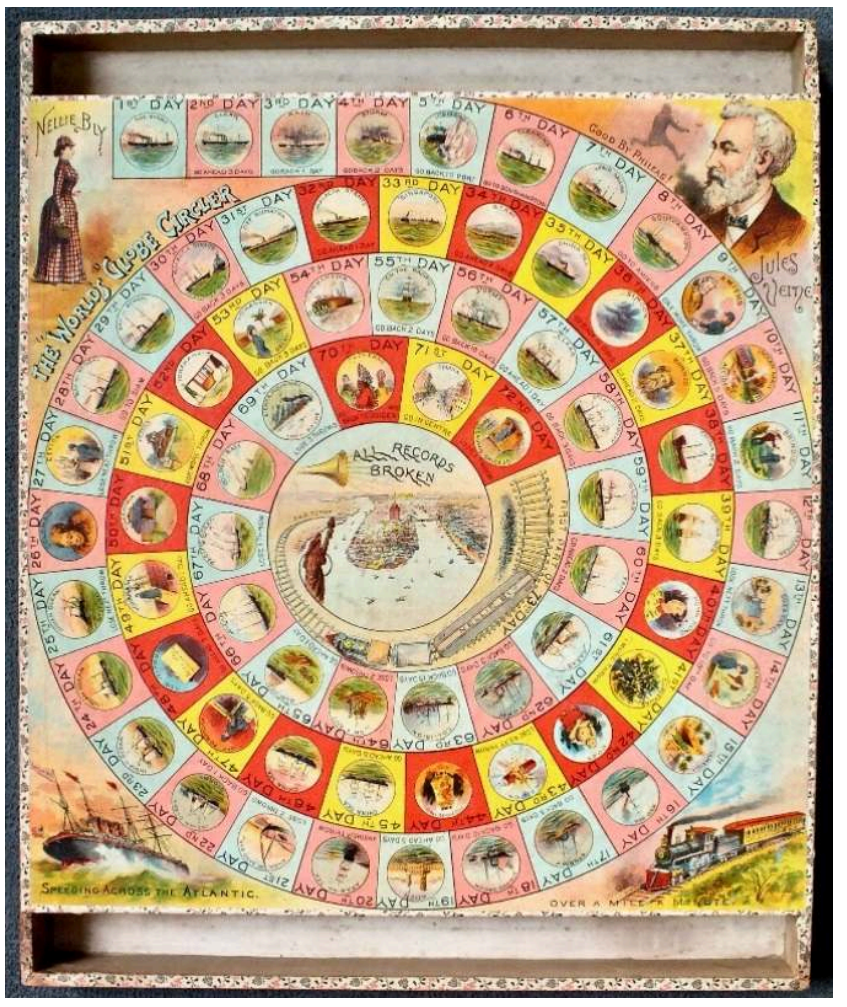

31 Les expositions universelles telles que celle de 1893 à Chicago fournissent de superbes visuels aux concepteurs. Lorsque le roman de George Du Maurier, Trilby (figure 11), est publié sous la forme d'un feuilleton dans le Harper's Magazine, il est instantanément traduit en jeu par E.I. Horsman. Peu après l'invention du télégraphe sans fil par Guglielmo Marconi, de nombreux jeux sur ce thème sont développés. La ruée vers l'or du Klondike, en Alaska, devient également un sujet récurrent (et lucratif) pour de nombreux éditeurs de jeu. La guerre hispano-américaine est rejouée à domicile par des milliers de personnes, les éditeurs produisant quelques jeux patriotiques qui participent (et bénéficient) de la popularité de Théodore Roosevelt, Georges Dewey (figure 12) ${ }^{15}$ ou encore du régiment des Roughriders. 
Figure 11 : Trilby, d'après le roman de Du Maurier (Horsman, 1895)

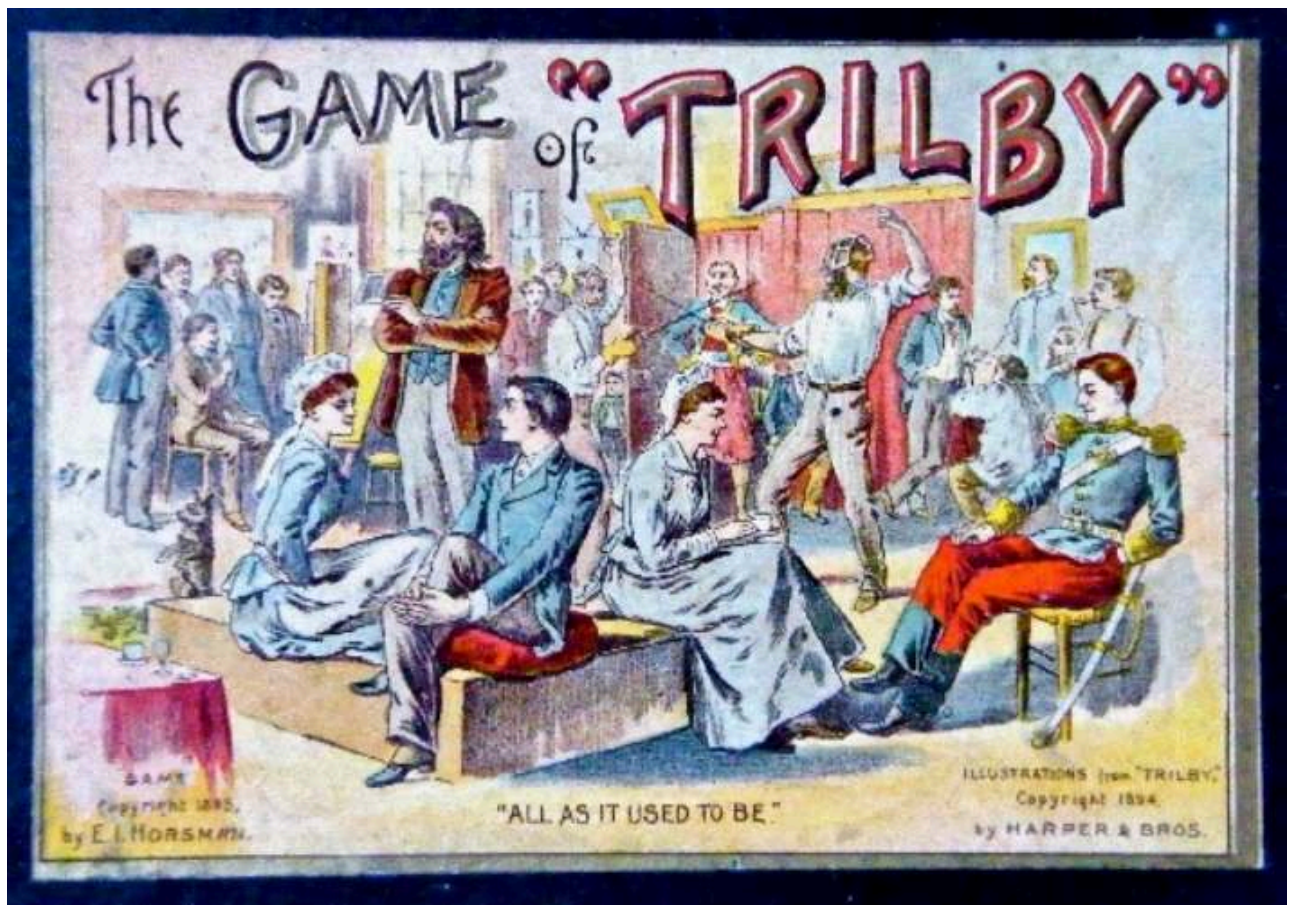

Figure 12 : Dewey at Manila, (Chaffee and Selchow, 1900)

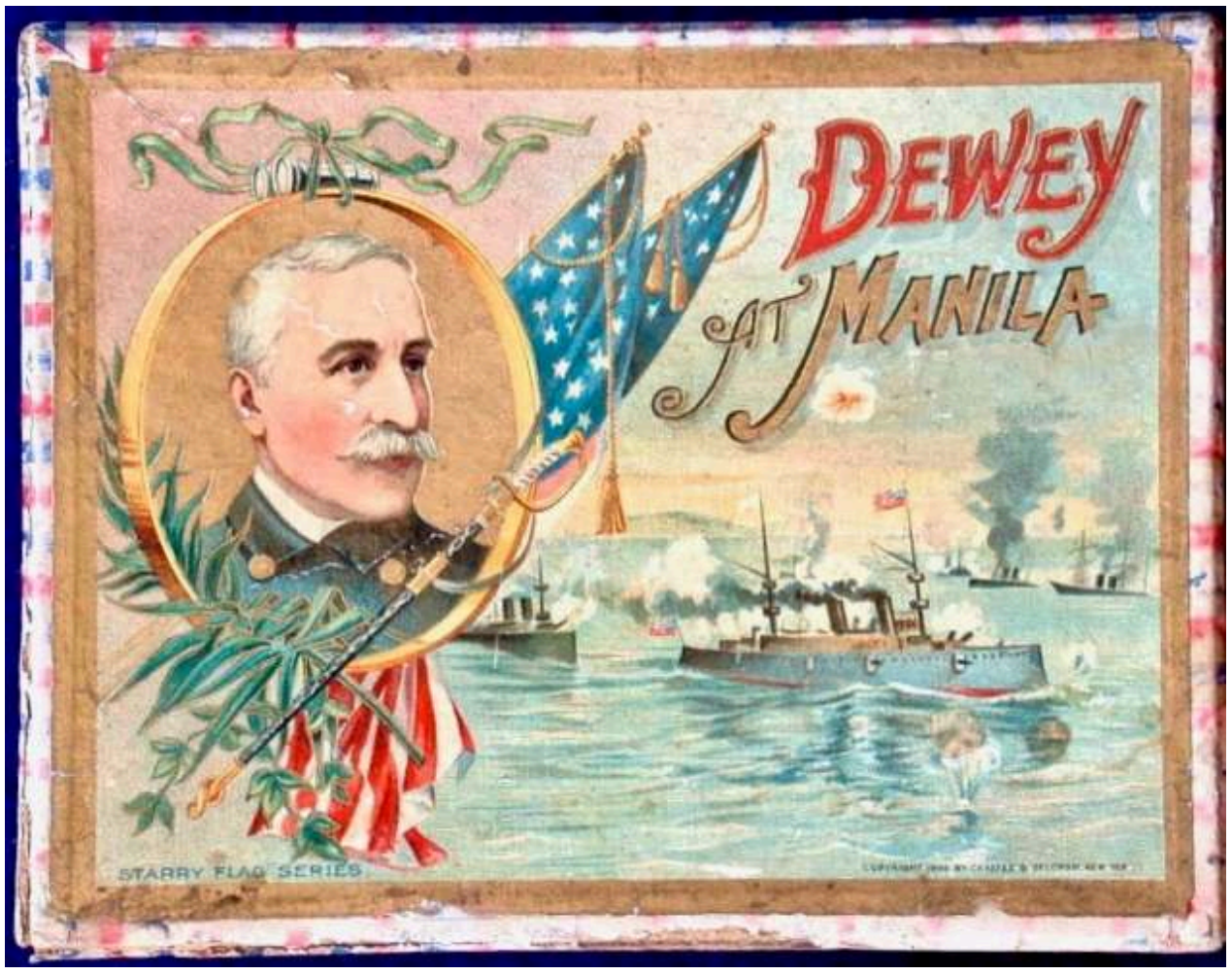

32 À travers cette production dans laquelle de nombreux événements deviennent des thèmes ludiques, on peut observer un changement éditorial: moins soucieux de l'éducation morale, civique et religieuse telle qu'elle était promue dans les productions 
précédentes, le secteur du jeu de société s'approprie progressivement des éléments plus divers de la culture populaire.

En 1893, Stewart Culin, éminent spécialiste des jeux des Premières Nations (1992), de Corée et d'Orient (1895), organise une exposition sur les jeux du monde à l'occasion de l'Exposition universelle de Chicago. Deux ans plus tard, il en développe une seconde pour l'Exposition internationale des États du coton à Atlanta. Largement connu et relayé, son travail fait alors découvrir aux États-Unis un patrimoine ludique ancien. Cet important travail d'archivage et de collection semble, dans un premier temps, n'avoir eu un impact que très indirect sur le secteur. Si le catalogue de Parker Brother de 1894 fait sa couverture sur le Yale-Harvard Game, jeu primé et récompensé à l'occasion de l'exposition universelle, il ne comprend aucun jeu ayant un lien évident avec ceux présentés par Culin. Outre le jeu de l'exposition universelle, il présente The Mansion of Happiness (nouvelle édition du jeu de Ives de 1864), The Office Boy ${ }^{16}$, dans lequel un jeune homme travailleur doit gravir les échelons pour devenir chef d'entreprise, The Soldier $B o y^{17}$ (où ce même jeune homme, avec un peu "de talent, de courage et d'ambition ", peut devenir «Commandant en chef »), Hoppity (variante du jeu Halma), Chivalry ${ }^{18}$ et enfin Across the Continent ${ }^{19}$.

Cependant, il est probable le travail de Culin ait pu susciter un intérêt pour les voyages dans le monde ou les lieux exotiques. Quelques jeux du catalogue Parker semblent en effet inspirés par cette invitation au voyage, notamment le titre Game of Travel ${ }^{20}$ (qui consiste en un aller-retour entre l'Amérique et Constantinople), Go-Bang, Royal Arabia, (un jeu «mahométan » joué par les "Turcs et les Arabes" sur une planche en bois ou incrustée), The Spanish Main, dans lequel un «marchand (essaie) d'entrer au port en toute sécurité, hors de portée de trois bateaux pirates » et Crossing the Ocean ${ }^{21}$ (dont le prix est de 30 centimes seulement). Si le catalogue de 1895 ne présente que peu de créations originales, Parker Bros présente l'année suivante Nyout un jeu qui se « jeu se joue sur vingt-neuf cercles ». La description du catalogue précise par ailleurs que « la mécanique de jeu et les instruments sont très nouveaux, et n'ont jamais été utilisés dans aucun autre jeu ». On peut néanmoins voir dans l'édition de Nyout une influence plus directe de certains jeux de l'exposition ou des écrits de Culin ${ }^{22}$.

\section{Nouveau siècle, nouvelle culture}

$\mathrm{Au}$ début du $20^{\mathrm{e}}$ siècle, les jeux de société, de cartes et d'adresse deviennent monnaie courante dans les loisirs américains. On peut y jouer pour le simple plaisir et non plus seulement pour les enseignements académiques ou moraux si souvent associés aux titres des décennies précédentes. La production de jeux de société n'est d'ailleurs plus un complément de revenu ou la ramification d'une entreprise, mais une activité pleine et entière. Quelques entreprises prospèrent avec l'édition, la vente ou la distribution de jeux de société. Au tournant de ce nouveau siècle, la société évolue rapidement. L'Amérique se développe vers l'ouest, alors que l'Oklahoma, le Nouveau-Mexique et l'Arizona (et, bien sûr, Hawaï et l'Alaska) ne sont pas encore des États. Dans le même temps, l'industrialisation entraine un exode du monde rural vers les villes tandis que l'immigration augmente de manière significative. Des progrès majeurs sont réalisés dans les domaines du transport et de la communication et les entreprises du secteur du jeu étendent progressivement leurs zones de vente. 
À mesure que la concurrence s'intensifie et que le marché s'agrandit, les entreprises se lancent dans une réduction des coûts. La production de grands jeux et de boittes en bois devient plus rare et l'on accorde moins d'attention à la qualité du dessin lithographique. En 1902, la même année où il importe le Ping-Pong aux États-Unis, Parker Brothers réduit le développement de nouveaux jeux de société et se concentre sur les jeux de cartes. L'éditeur distribue le titre désormais classique Flinch, suivi de deux autres, Pit et Rook, en 1904 et 1906 (figure 13). Ce dernier, inventé par George Parker, devient le jeu de cartes le plus vendu. En 1909, l'éditeur se lance dans la fabrication d'une gamme de puzzles en bois d'une qualité exceptionnelle. La société y consacre l'essentiel de sa production qui connait les deux décennies suivantes un véritable engouement.

Figure 13: Pit (Parker Bros, 1919), Rook (Parker Bros, $\pm .1920 s)$, Flinch, (Parker Bros, 1938)

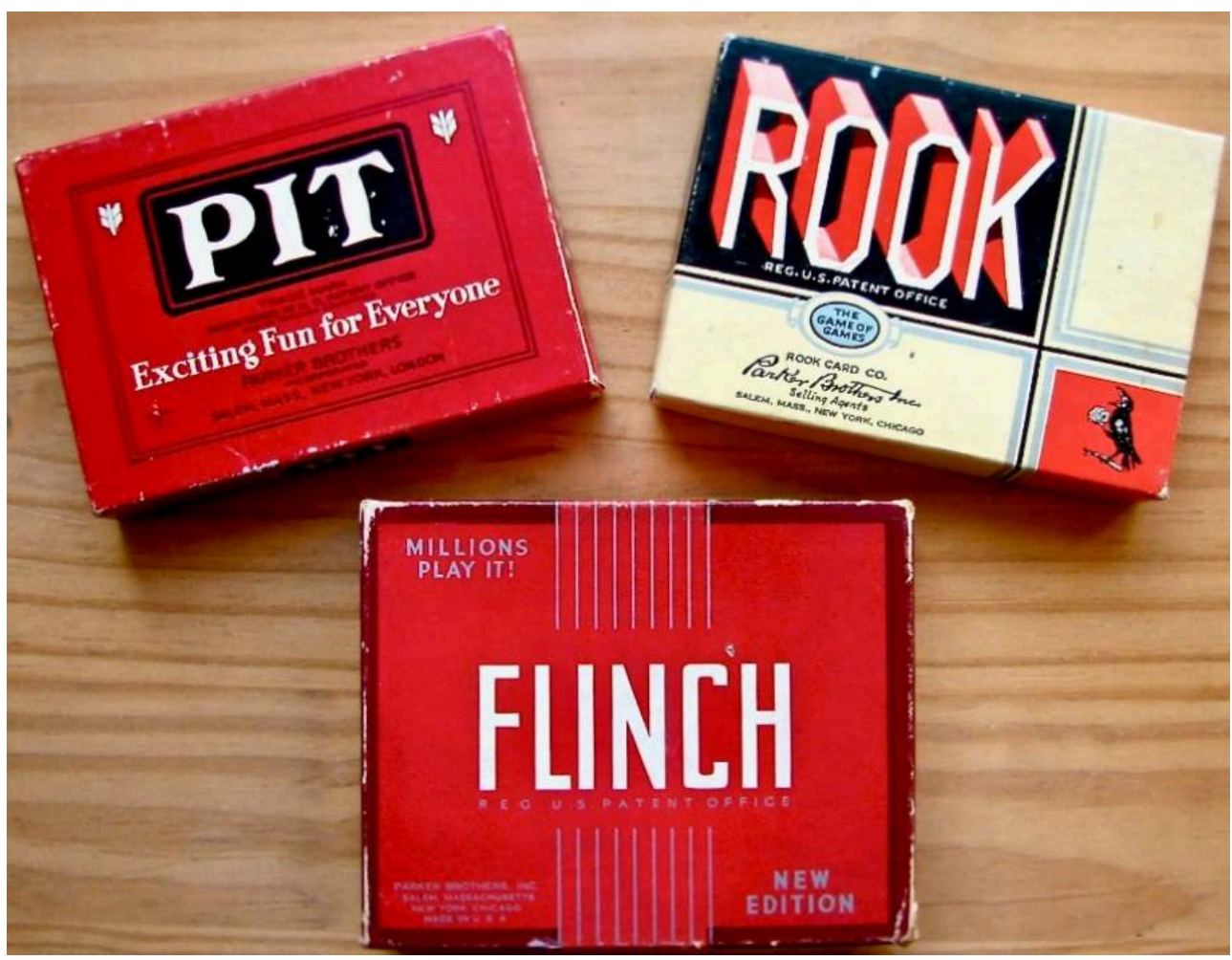

37 La panique bancaire américaine de 1907 marque un premier ralentissement du secteur suivi d'un second plus important lors de la Première Guerre mondiale qui voit la disparition d'un grand nombre de petites entreprises actives lors du siècle précédent, telles que Clark \& Sowdon et Ottmann. L'éditeur J.H. Singer fait faillite tandis que Rufus Bliss et E.I. Horsman cessent la fabrication de jeux. Le secteur est d'autant plus troublé qu'au début de ce nouveau siècle les fondateurs des entreprises pionnières disparaissent et leur gestion se voit assurée par leurs héritiers. En 1915, John McLoughlin, Milton Bradley, Elisha Selchow et John Righter sont morts. En 1920, l'un des frères McLoughlin décède et la société est rachetée par Milton Bradley. L'industrie du jeu de société est en difficulté et sa restauration est dans les mains d'une nouvelle génération d'entrepreneurs.

Les « années folles ", époque de gaieté, mais aussi de tensions urbaines, vont se révéler propices pour l'industrie du jeu. La fin de la Première Guerre mondiale permet en effet 
de se consacrer à nouveau au marché intérieur après le soutien demandé aux industries à l'effort de guerre. Dans un contexte favorable au loisir et au divertissement, de nombreux jeux, aujourd'hui classiques, voient le jour. Uncle Wiggily (figure 14), personnage d'une série d'histoires pour enfants d'Howard Garis, est l'objet d'un jeu éponyme en 1916, et voit ses ventes augmenter à mesure que la vie familiale américaine revient à la normale. Sensiblement à la même période, Chinese Checkers ${ }^{23}$, diffusées par une nouvelle société, J. Pressman Co., connait un certain succès. La découverte du tombeau du roi Tut en 1922 renforce l'intérêt pour l'exotisme et une multitude de jeux ayant pour thèmes et illustrations l'Orient sont édités. Parker Bros et Milton Bradley, ainsi qu'un nombre important de petites entreprises, profitent dans le même temps de la mode du Mah Jong aux États-Unis.

Figure 14: Uncle Wiggily (1937, Milton Bradley)

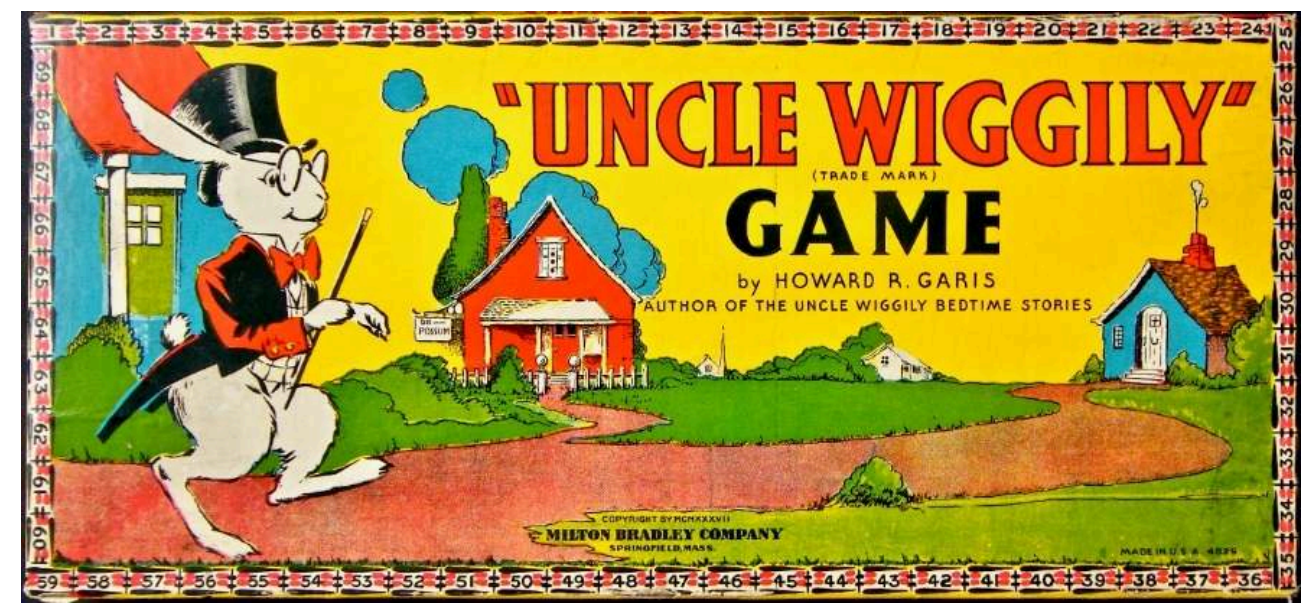

Située au nord de l'État de New York, l'entreprise Alderman-Fairchild (All-Fair), qui fabrique notamment des cartons, se lance dans la production de jeux de société (et de fléchettes), tandis qu'une nouvelle société à St. Louis, Wilder, édite de nouveaux titres avec une lithographie particulièrement élaborée. Saalfield, éditeur de livres, ajoute des jeux à son catalogue en 1911. La société Wolverine Supply \& Mfg. se lance également dans la fabrication de jeux sur des planches de métal lithographiées. En 1927, Selchow \& Righter Co. cesse de distribuer les jeux des autres sociétés pour développer ses propres produits. Créée en 1916, l'union professionnelle "Toy Manufacturers of America ", dont le siège social est à New York, devient une institution majeure et centrale du secteur.

Au cours de ce nouveau siècle, les jeux de société continuent de s'inspirer de nombreux événements dans le monde et reflètent le développement d'une Amérique en pleine croissance: de l'invention du Zeppelin à Phoebe Snow, personnage publicitaire introduit en 1900 par la compagnie de chemin de fer DL\&W pour promouvoir sa nouvelle ligne confortable et propre. L'ours en peluche Teddy, popularisé après que Theodore Roosevelt a épargné la vie d'un ourson au cours d'une partie de chasse, devient une image fréquente sur les boîtes et les cartes de jeu ${ }^{24}$ (figure 15). Toutes sortes d'animaux, anthropomorphisés, commencent d'ailleurs à apparaitre sur les boîtes de jeu, en même temps que les "danses animales " 25 à la mode entre 1911 et 1913, telle le « Turkey Trot ${ }^{26}$, font danser le pays. L'exploit de Robert Peary qui atteint le pôle Nord en 1909 et le voyage deux ans plus tard de Roald Amundsen au pôle Sud donneront naissance à des jeux ayant pour thème l'exploration polaire. Amundsen, qui 
avait participé au premier vol au-dessus du pôle Nord, emprunte le passage du NordOuest, qui deviendra le titre de plusieurs jeux de société.

Figure 15: Teddy's Bear Hunt, (Bowers \& Hard, 1907)

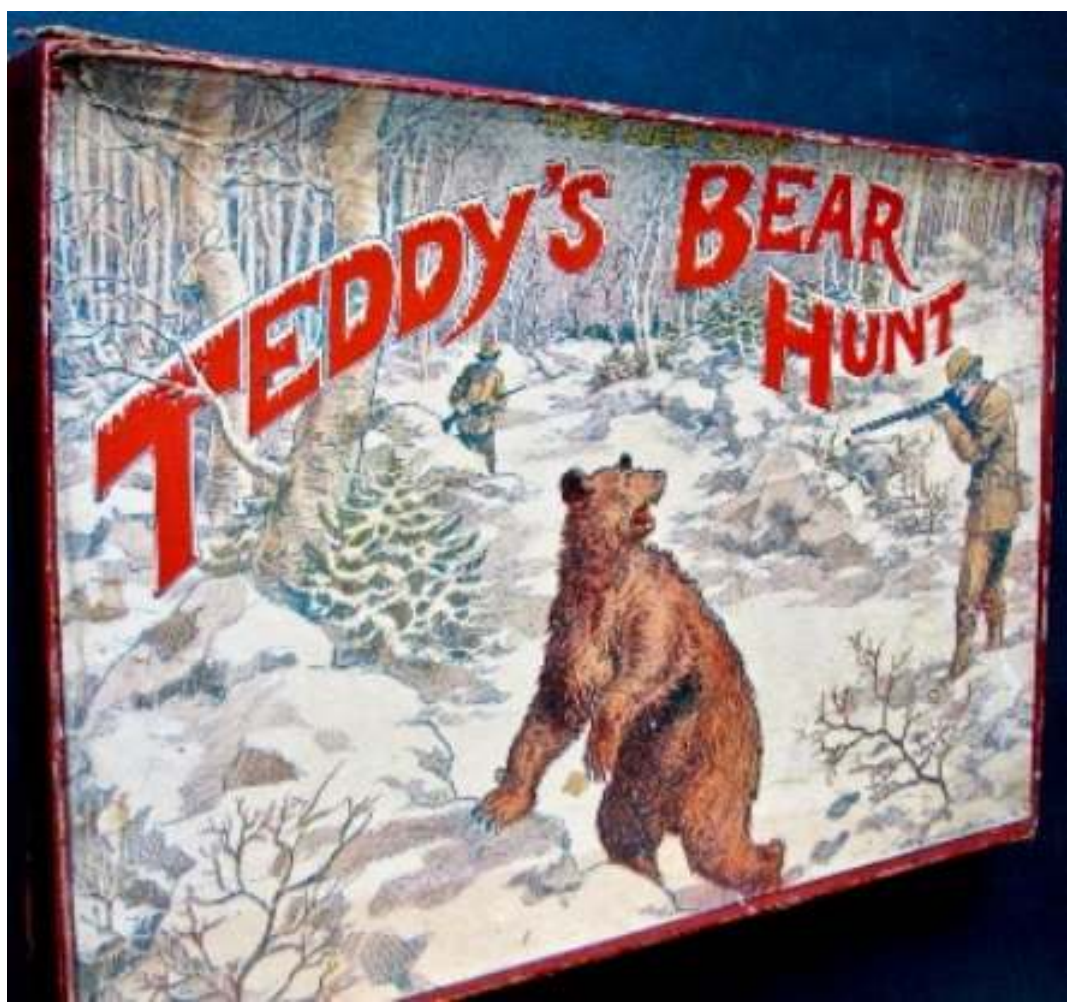

On constate sur la période une prédilection des éditeurs pour certains thèmes: la première route aérienne continentale, le vol de Lindberg, le développement de l'aviation commerciale, la construction par l'amiral Byrd de la base «Little America " en Antarctique (figure 16), le canal de Panama, ou encore l'essor de la radio et l'émergence des premiers centres commerciaux. La fascination de l'Amérique pour les transports et les voyages, mais aussi l'obsession de la nation pour l'automobile se manifeste dans de nombreux jeux. 
Figure 16: Admiral Byrd Little America, (Parker Bros, 1930)

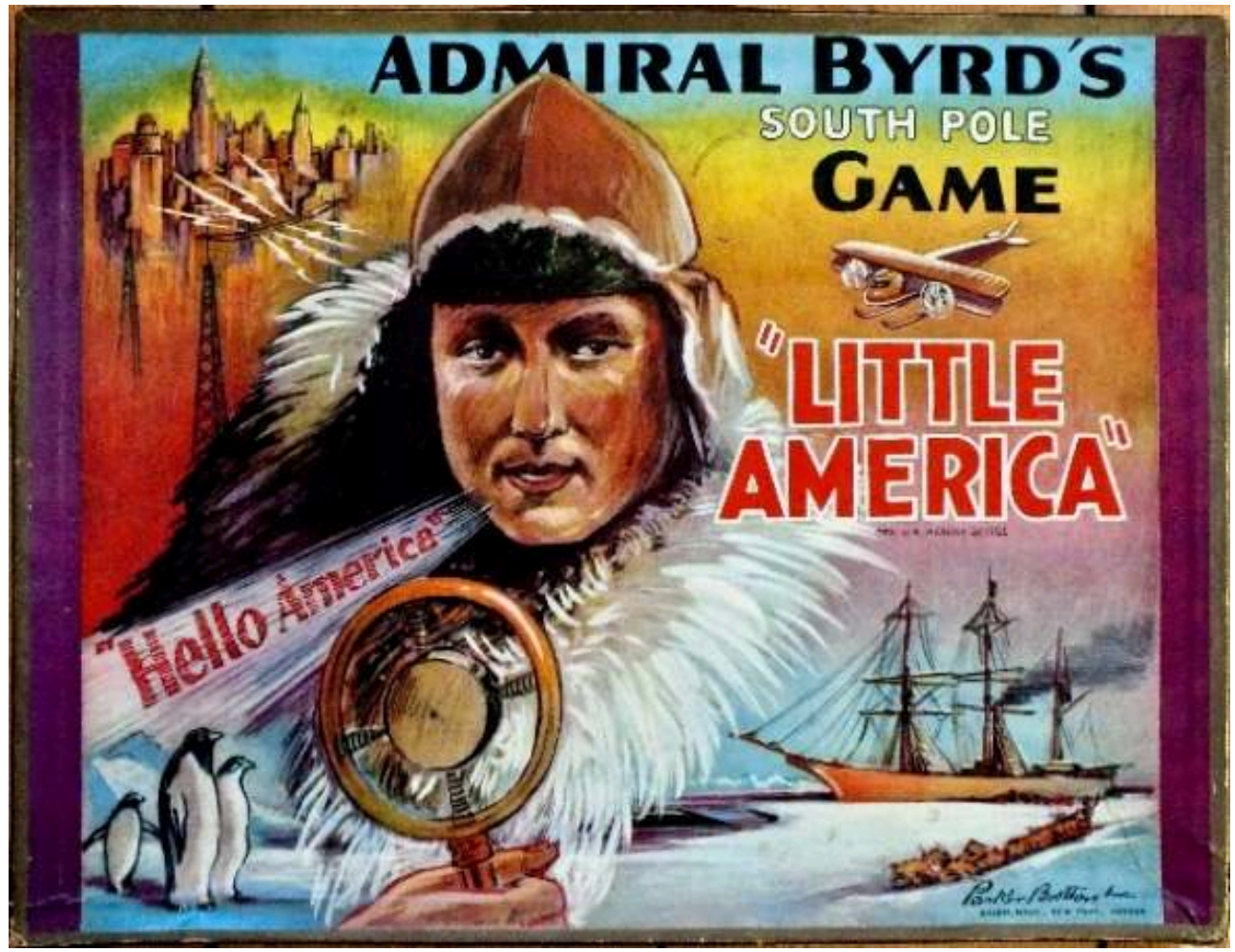

Figure 16 bis: Admiral Byrd Little America gameboard, (Parker Bros, 1930)

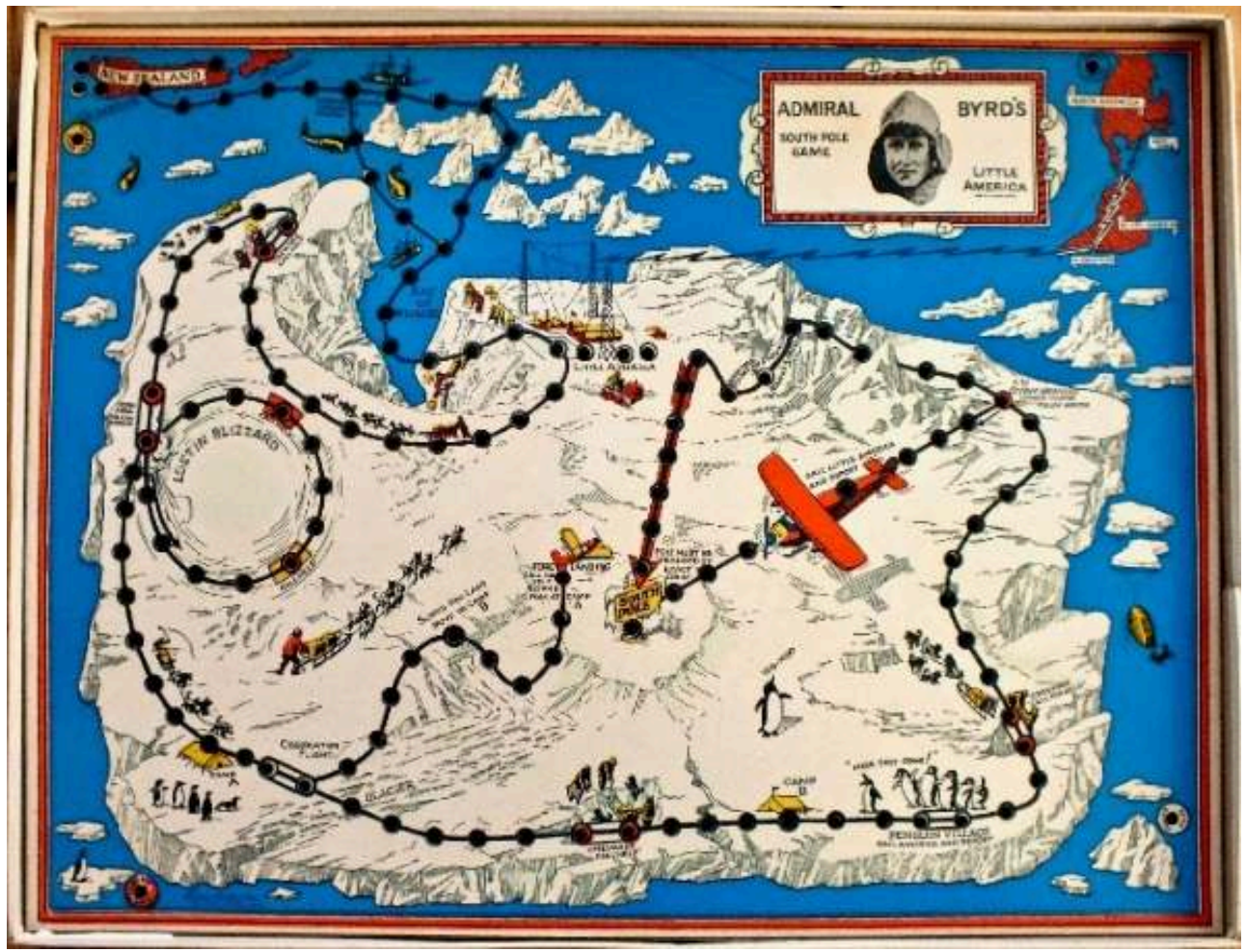

42 Dans le monde de la publicité, le jeu de société devient progressivement un support employé pour promouvoir des produits. Mais sous la forme de cadeaux et de récompenses, ils se voient aussi directement insérés dans des marchandises. La 
Woolson Spice Co. de Toledo, Ohio, associe ainsi à son café «Lion » près de 60 jeux de cartes différents et de nombreux petits jeux de société en carton mince et aux thèmes divers (figures 17 et 18), allant d'Abraham Lincoln (From Log Cabin to White House ${ }^{27}, 1895$ ) à celui du cirque (1903).

Figure 17 : Game of Buy and Sell, Lion Coffee (Woolson Spice Co., $\leq 1903$ )

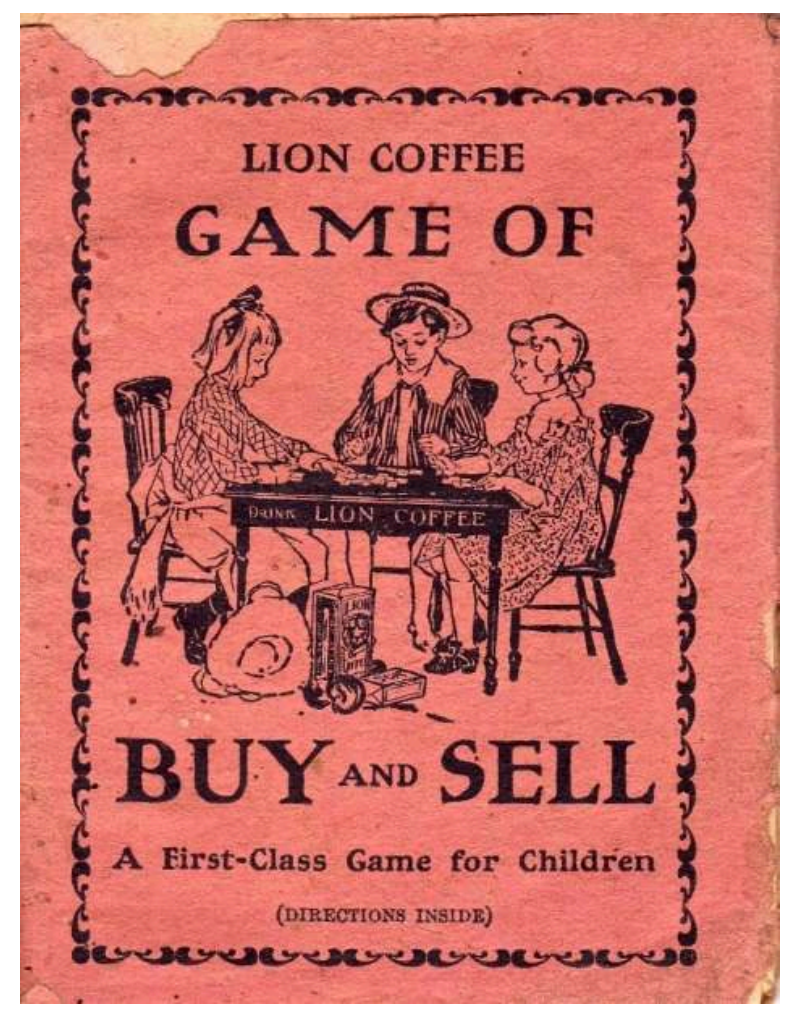


Figure 18 : Publicité pour le café Lion, autour de 1903

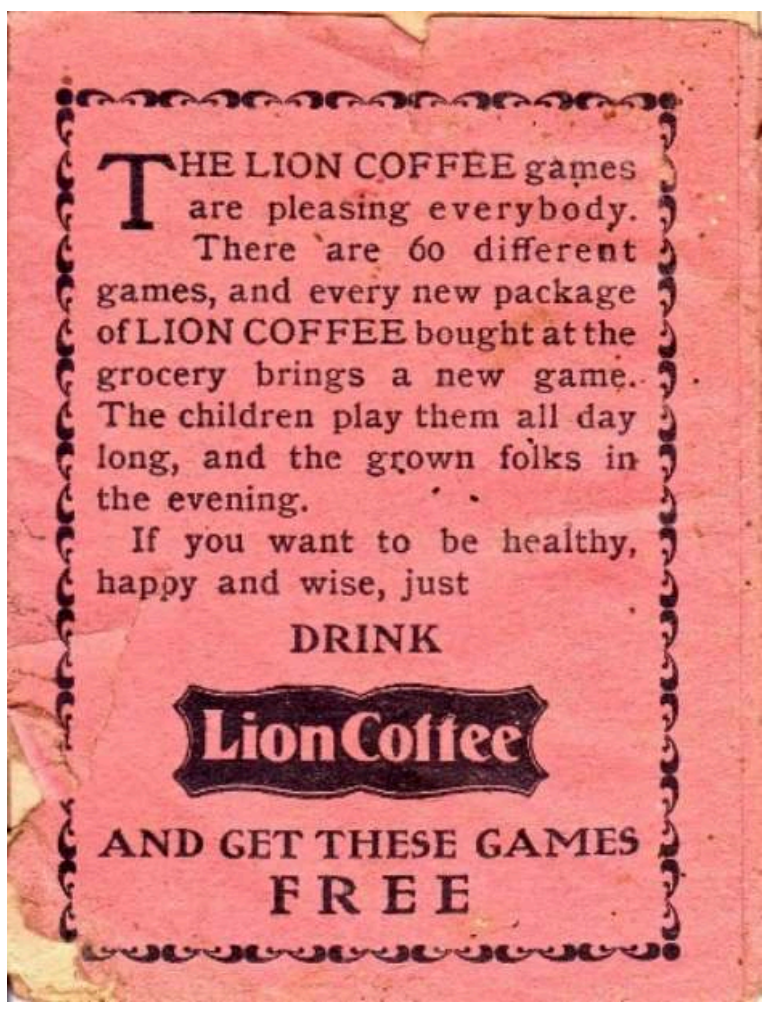

43 Sur cette période, le football américain, le golf, le basket-ball et surtout le base-ball sont fréquemment miniaturisés et adaptés en jeux de société pour être pratiqués sur une table. Certains sports sont privilégiés comme les courses automobiles, à l'image du titre Vanderbilt Cup Race (figure 19), premier jeu sur ce thème qui se présente sous la forme d'un parcours traversant les villes de Roslyn, Lakeville et Old Westbury, et les villes de Long Island lieu ${ }^{28}$.

Figure 19: The Vanderbilt Cup Race (Bowers \& Hard, Connecticut, vers 1906)

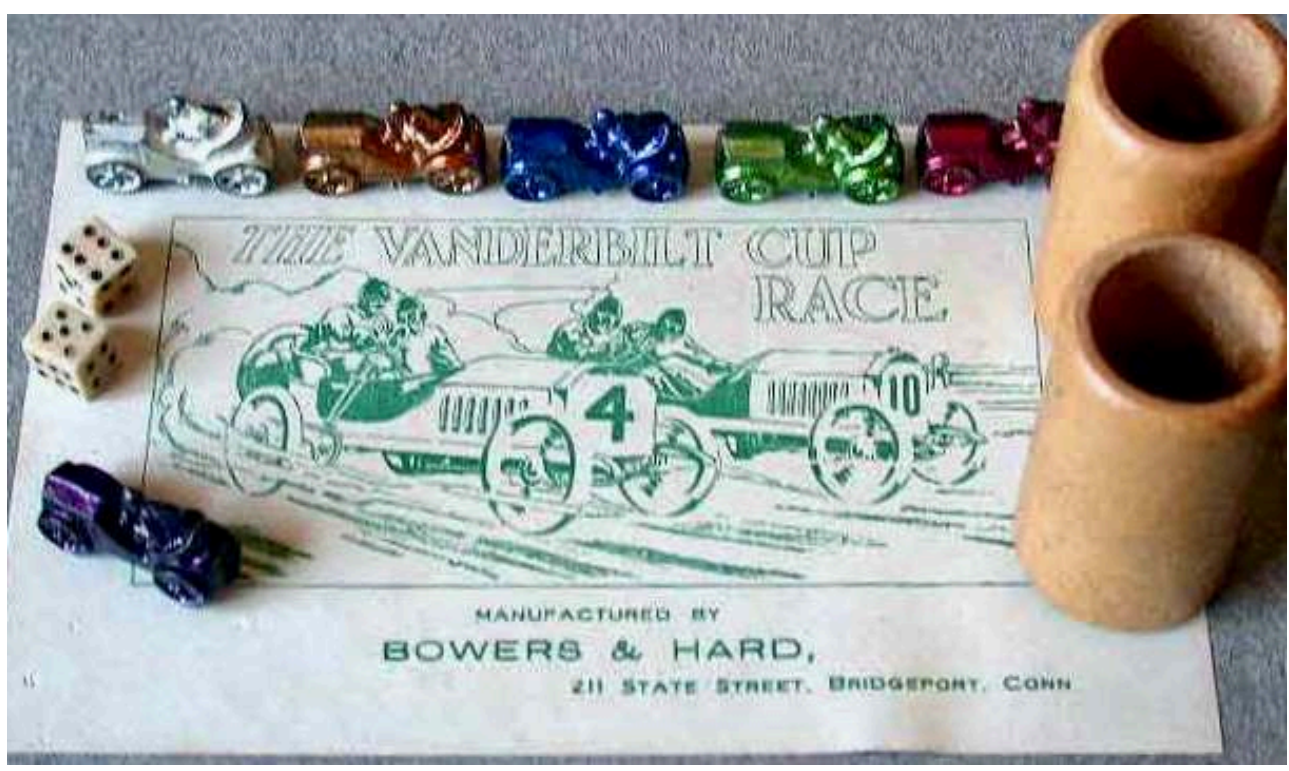


Des contes de fées et des comptines, telles que Mistress Mary, Quite Contrary (Parker Bros., 1905) se voient traduits en jeu. Des activités de plein air comme le «Tir au canard $^{29}$ ", qui consiste à lancer de petites pierres sur des boîtes de conserve placées sur un gros rocher, sont adaptées pour être jouées en intérieur (figure 20). Les jeux de divination (figure 21) se multiplient également. La création des Scouts aux États-Unis deux ans plus tard donne presque immédiatement lieu à la création de jeux sur cette thématique.

Figure 20 : Duck on the Rock (Milton Bradley, autour de 1910)

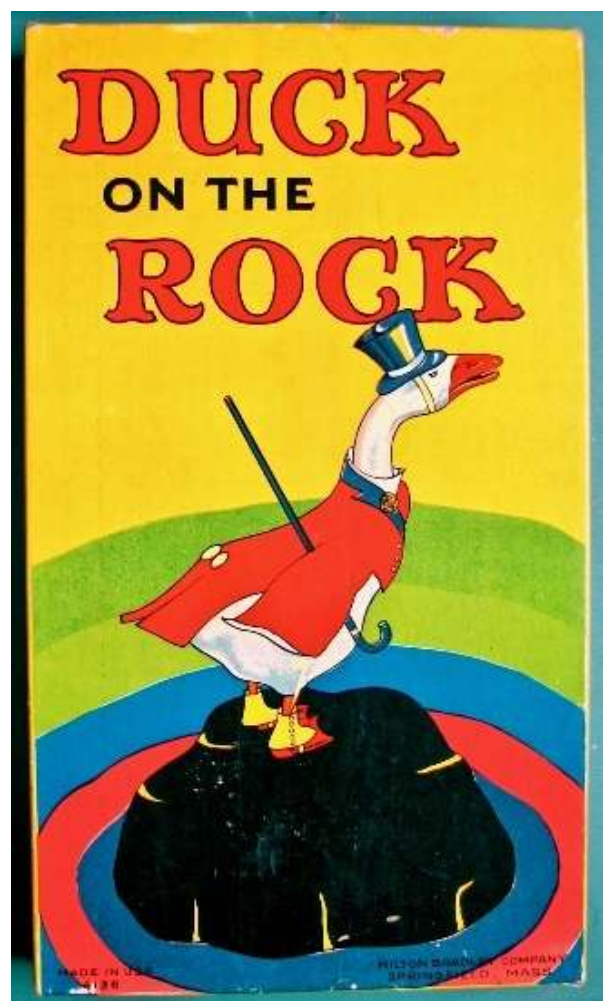


Figure 21 : The Game of Fortune Telling, (éditeur inconnu, autour de 1910)

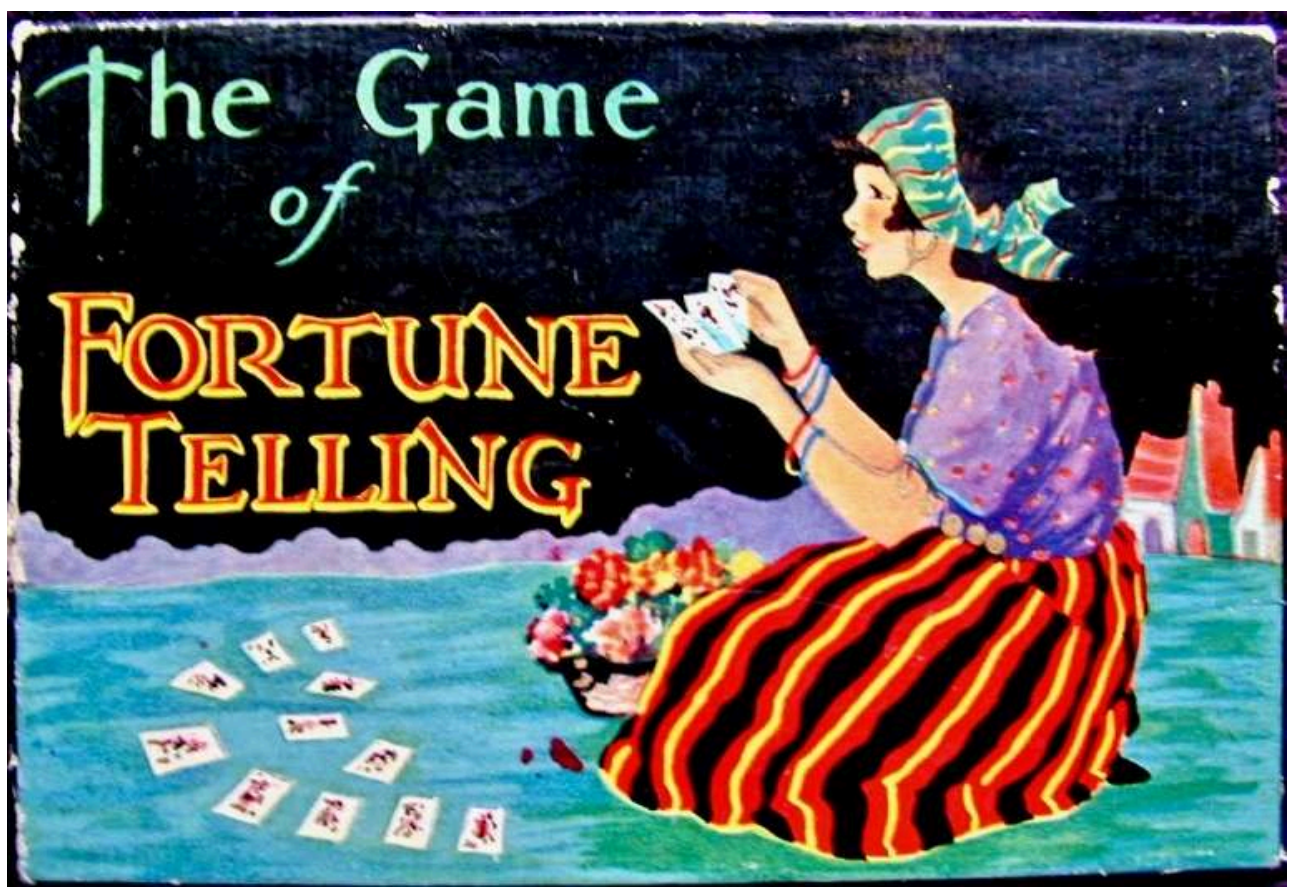

En 1911, M.B. édite la première version d'un jeu qui restera populaire jusque dans les années 1950, Pirate and Traveller $^{30}$ (figure 22) : malgré la faute d'orthographe sur la boîte, le jeu est " recomandé [sic] par les éducateurs dans le cercle familial ». Édité par Parker Bros la même année, le jeu Pollyanna titre éponyme du roman de l'Américaine Eleanor H. Porter, est l'objet d'une série de jeux. Dans le même temps, le cinéma, qui passe du muet au sonore, devient un lieu d'emprunt. Un ensemble d'événements historiques continuent d'être des sujets ludiques, à l'image du jeu Chasing Villa ${ }^{31}$ (figure 23), édité de façon inattendue par Smith, Kline \& French, une firme pharmaceutique de Pennsylvanie. Le titre met en scène les 11 mois de fuite de Pancho Villa au Mexique, poursuivi par l'armée américaine pour avoir tué plusieurs civils. 


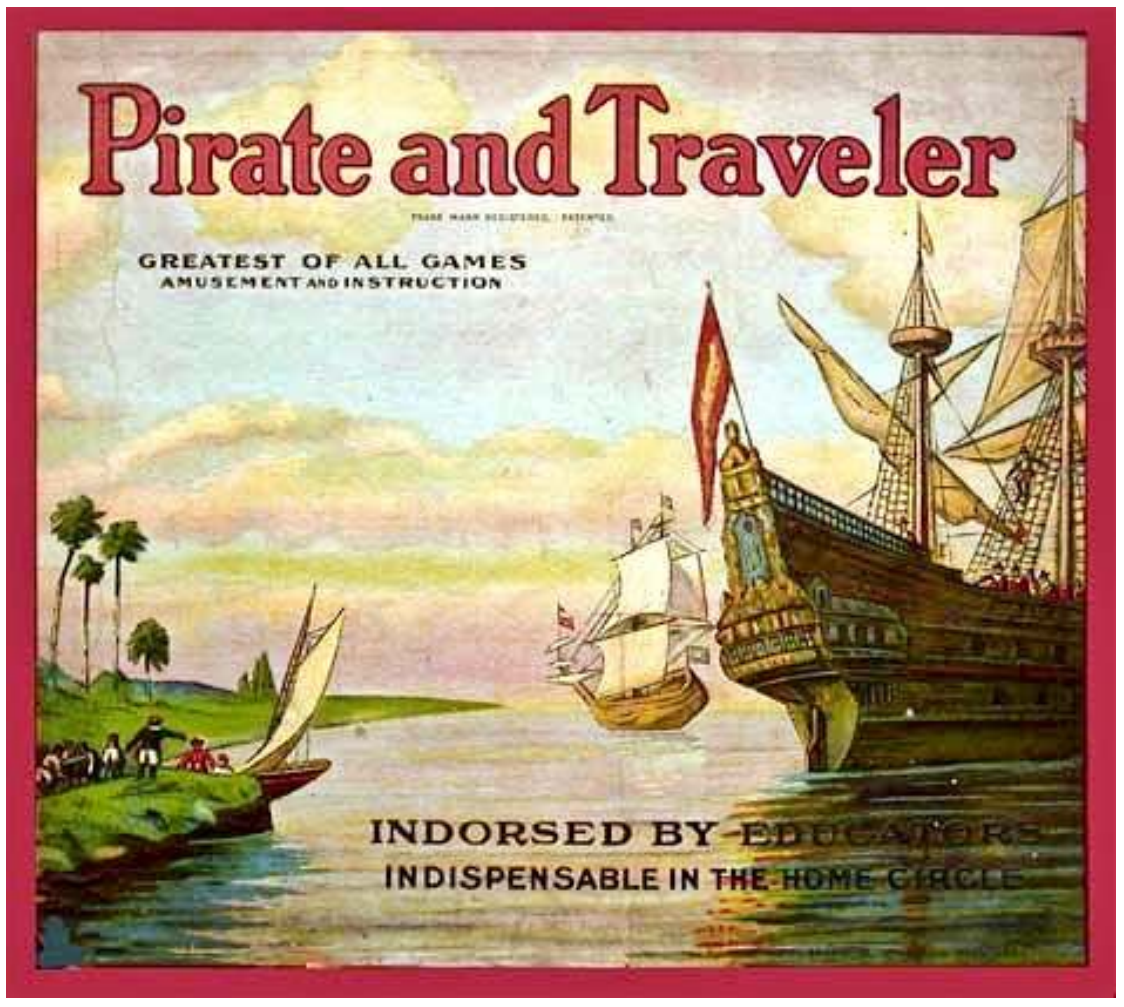

Figure 23 : Chasing Villa (Smith, Kline and French, 1920)

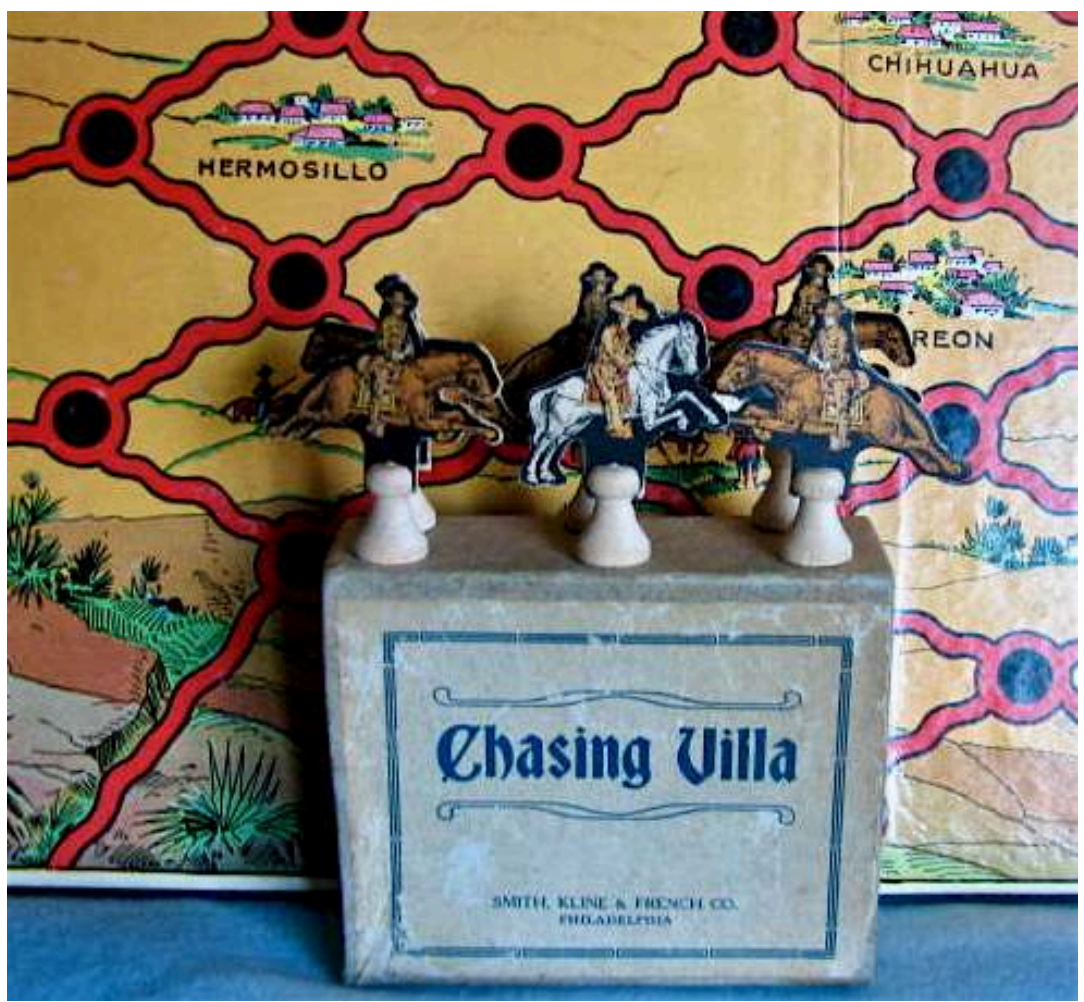

Les adaptations de dessins animés en jeux de société font également leur première apparition dans cette période, avec Foxy Grandpa ${ }^{32}$, en 1906, inspiré de la bande dessinée 
populaire de Carl «Bunny" Schultz, ou encore Walt \& Skeezix: Gasoline Alley Game d'après la bande dessinée Gasoline Alley de Frank King. Toutes deux sont éditées par M.B. De la même façon, le recours à des auteurs de bande dessinée devient plus fréquent. Bringing Up Father ${ }^{33}$ Game (figure 24) fait appel à George McManus, tout comme les titres Keeping Up With the Joneses (Phillips) illustré par A.R. "Pop" Momand ou encore Barney Google \& Spark Plug (figure 25) par Billy De Beck.

Figure 24 : Bringing Up Father et Keeping Up With the Joneses (H.J. Phillips Co., 1920, 1921)

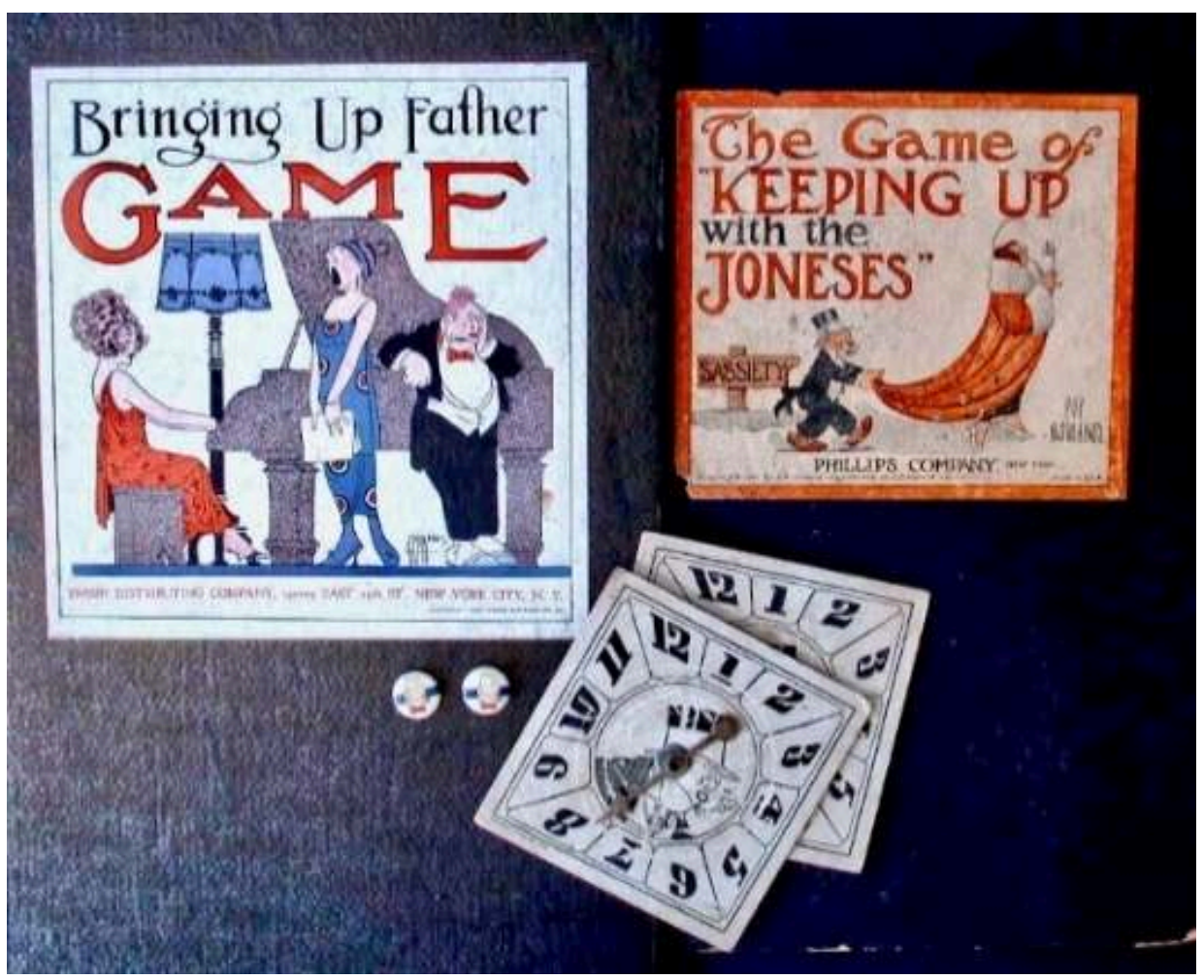

Figure 25 : Barney Google \& Spark Plug (Milton Bradley, 1923)

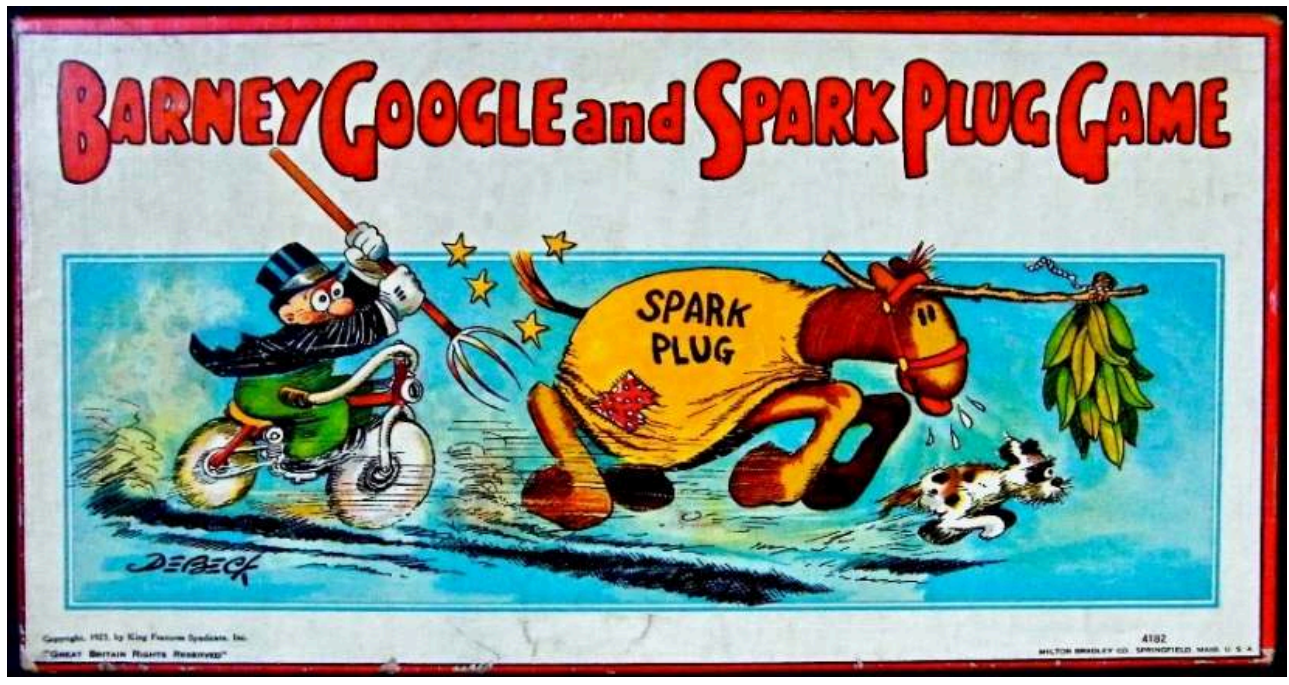

47 L'année 1929 marque le début de la Grande Dépression. Comme pour le cinéma, dont l'entrée dans les salles reste peu coûteuse même en période de troubles, la crise est peu 
ressentie par l'industrie jusqu'en 1932. Le backgammon connait même un regain d'intérêt et les puzzles une popularité accrue. En 1930, l'intérêt pour le minigolf (qui apparait dans la région du Tennessee) continue de grandir, comme en témoignent les nombreux de jeux de golf miniatures présents sur le marché. Deux évènements vont inspirer les productions de la période : la création par la compagnie United Airlines de son premier service d'hôtesses de l'air, et le vol du China Clipper de la Pan American qui permet à ses passagers de traverser le Pacifique. Inauguré en 1931, l'Empire State Building, alors le plus haut bâtiment du monde, devient rapidement une nouvelle icône mobilisée sur les plateaux de jeu et les couvercles de boîtes.

Créées dans le cadre du New Deal pour soutenir et stimuler l'économie, des institutions telles que la National Recovery Administration (NRA), la Tennessee Valley Authority, ou celle de la Works Progress Administration éditent quelques jeux en lien avec le monde du travail (figure 26). Comme le laisse entrevoir l'exposition universelle de Chicago en 1933-34, aussi connue sous le nom de "Siècle du progrès ", la sortie de crise est pour bientôt et les titres de jeux liés à la finance et à l'économie se multiplient. Alors qu'il l'avait refusé deux ans plus tôt, l'éditeur Parker Bros accepte de publier en 1934 un jeu de Charles Darrow, un jeune auteur alors inconnu : le Monopoly.

Figure 26: Game of Prosperity (NRA, autour de 1933)

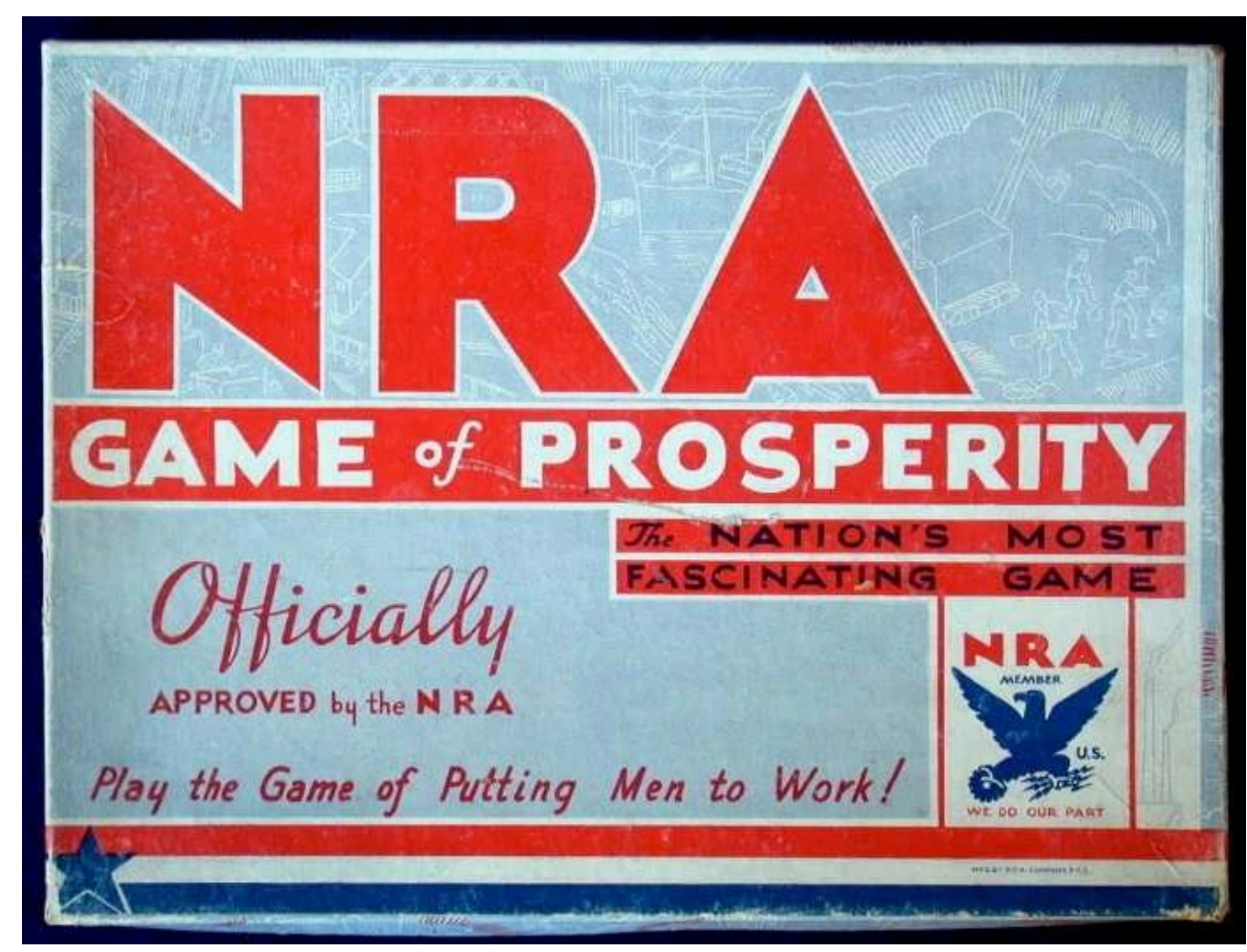

\section{La grande affaire du Monopoly}

La publication du Monopoly en 1935 marque un tournant important de l'industrie du jeu de société. Aucun jeu propriétaire n'avait jusqu'ici gagné une telle popularité dans le monde. L'une des raisons les plus souvent avancées pour expliquer son succès est le contexte, créé par la Grande Dépression, favorable à l'émergence d'un jeu qui permet à ses joueurs d'acheter symboliquement des propriétés et de gagner des millions. Si une 
telle hypothèse est séduisante, on peut cependant se demander pourquoi un jeu similaire, Easy Money (figure 27), édité quelque temps avant par M.B., n'a pas rencontré de succès comparable. Très proche du Monopoly, il comportait des cartes de propriétés qui ont disparu dans les éditions suivantes à la suite d'un accord avec Parker Bros.

Le Monopoly, que l'on pense souvent comme un produit de la Grande Dépression, est en

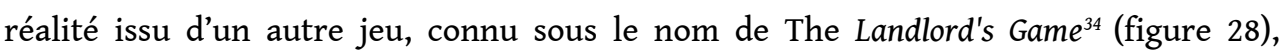
inventé et breveté par Elizabeth Magie en 1904. Dans le sillage des travaux de l'économiste Henry George, l'autrice souhaitait à travers ce jeu promouvoir les bienfaits du concept de l'impôt unique. Elle avait conçu un dispositif ludique dont la mécanique mettait en évidence l'impasse dans laquelle menait un système de propriétés où chaque joueur cherche à devenir «monarque du monde». Le jeu fut adapté dans différentes écoles pour l'enseignement de l'économie, notamment à l'université de Columbia, où le plateau emprunta alors les noms des rues de New York.

Figure 27 : Easy Money (Milton Bradley autour de 1935)

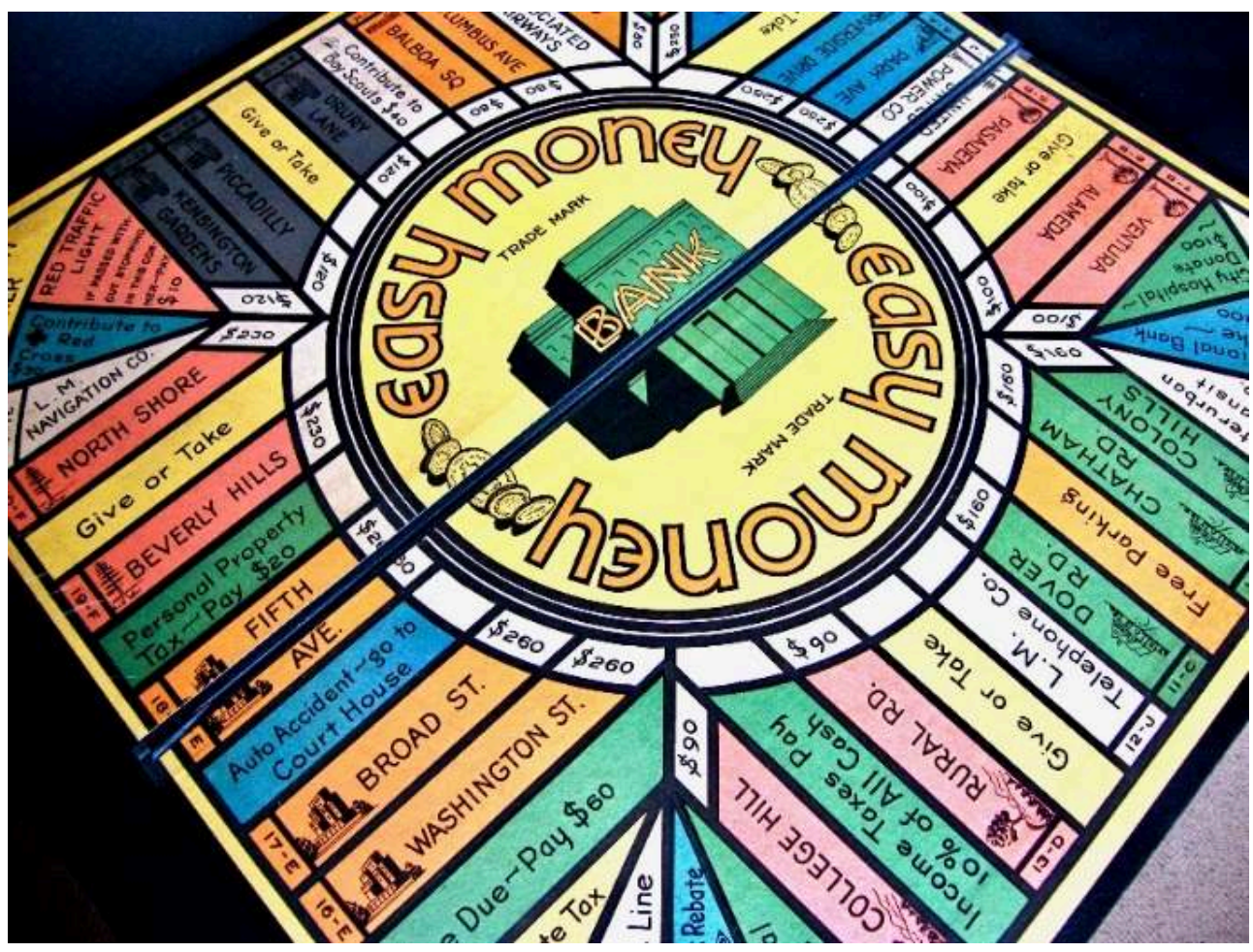


Figure 28 : The Landlords Game (reproduction de la version de l'université de Columbia 1924-29)

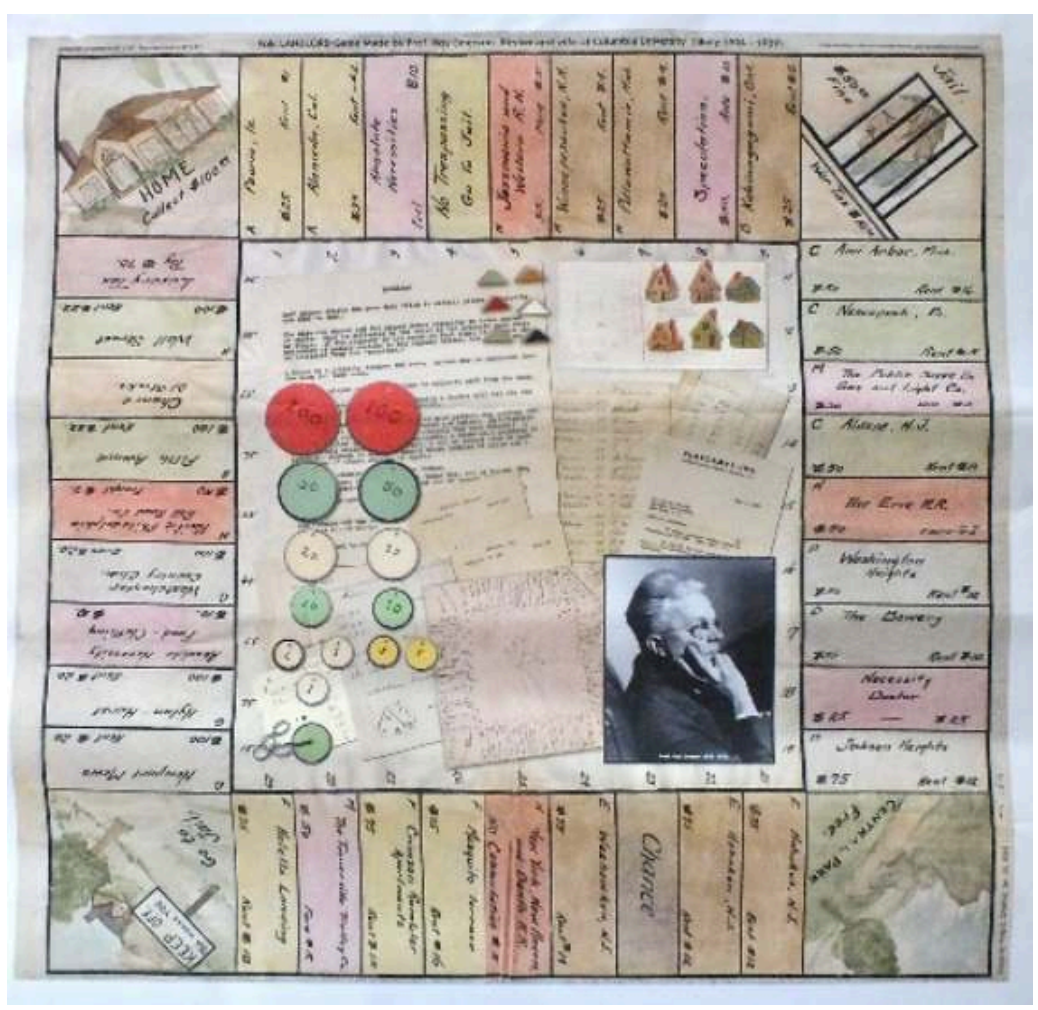

51 The Landlord's Game connait un certain succès en particulier sur les campus universitaires. Au cours de ses trente années de diffusion, le jeu perd progressivement son objectif premier. La seconde moitié de la partie, qui promouvait le système de l'impôt unique, est écartée, laissant le jeu tel que nous le connaissons aujourd'hui : une course pour la domination financière et immobilière. Le jeu est pratiqué dans de nombreuses régions du pays et reçoit à partir de 1910 l'appellation populaire de Monopoly dans certains endroits. Les cases du plateau se voient régulièrement rebaptisées localement selon le nom de rues, celles d'Atlantic City notamment où le jeu fut introduit et pratiqué par une communauté de Quakers.

Longtemps considéré comme son inventeur, Charles Darrow découvre ce jeu par l'intermédiaire d'un ami, Charles Todd. Ce dernier, qui avait copié le plateau de la version d'Atlantic City, avait d'ailleurs mal orthographié le nom de la rue "Marven Gardens » en « Marvin Gardens ». L'erreur est restée sur le plateau que Darrow dépose et protège légalement en 1933. Proposé à Parker Brothers un an plus tard, l'éditeur refuse dans un premier temps sa publication, soulignant 49 problèmes posés par le jeu parmi lesquels sa trop longue durée. Charles Darrow imprime alors environ 500 exemplaires et vend le Monopoly à son compte. La version qu'il propose ne comprend pas de pions, mais invite les joueurs à utiliser des objets ménagers courants tels que des boutons ou des clés. Après avoir appris que Darrow réussissait à vendre son jeu, et parce qu'un ami de la famille Parker l'avait fortement recommandé, l'éditeur achète finalement les droits et commence à le produire en 1935. Rich Uncle Pennybags ${ }^{35}$, le personnage moustachu, apparait sur le plateau, la boîte et les cartes un an plus tard.

De nombreux autres titres de cette période sont en réalité redevables du travail d'Elizabeth Magie : le jeu Finance, édité par Finance Game Co. puis par Knapp Electric, Finance and Fortune (figure 29) de Parker Bros., Easy Money chez M.B., et 
vraisemblablement Big Business de Transogram (figure 30). Tous sont des dérivés de The Landlord's Game et tous sont présents sur le marché dès 1936. Beaucoup de ces titres partageaient le même numéro de brevet que celui d'Elisabeth Magie - qui déposa un second brevet sous son nom marital, Phillips, pour une version révisée de son jeu en 1924. Présentée un temps comme « la célèbre autrice » de jeux chez Parker Brothers, l'éditeur créditera Mme Phillips comme l'inventrice du Monopoly jusqu'à l'expiration de son brevet.

Figure 29 : Finance et Finance and Fortune (Parker Bros, 1930-1950)

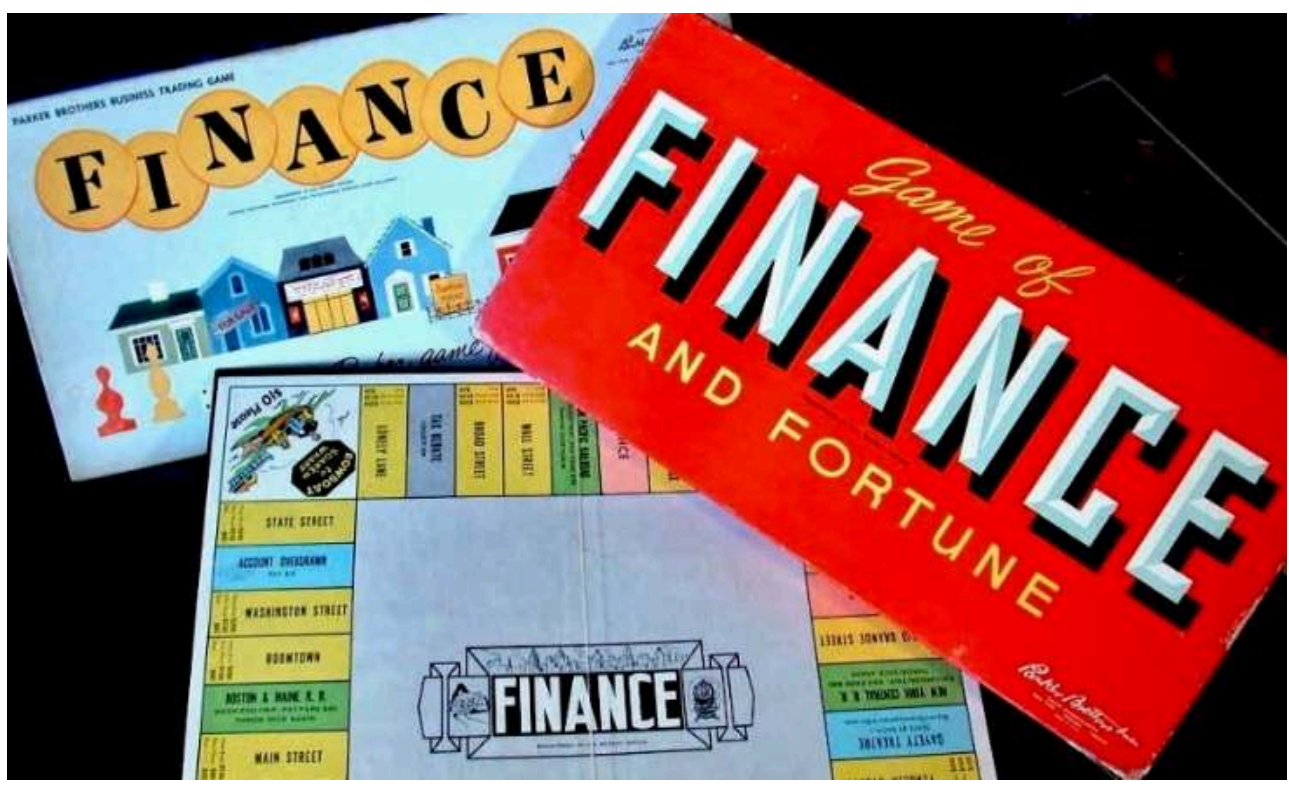




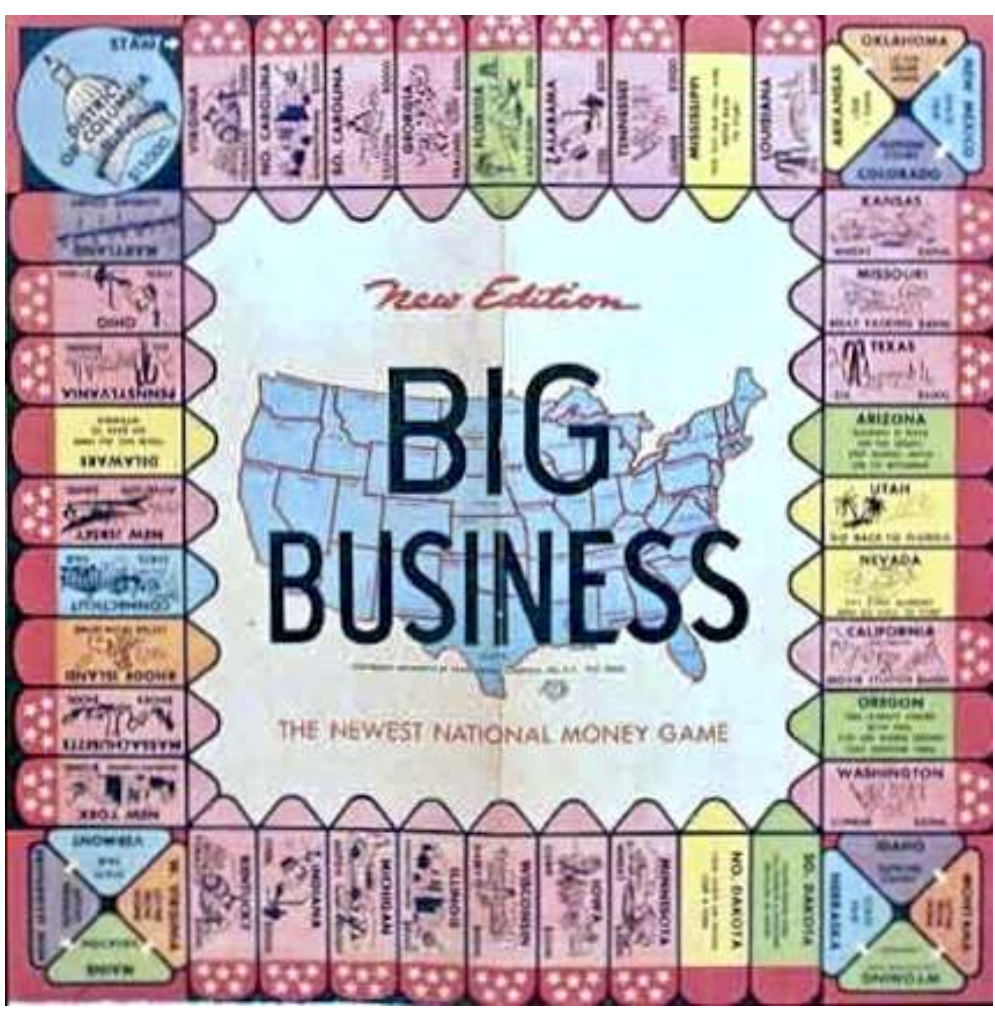

Dans l'ouvrage The Monopoly Companion de Philip Orbanes (dont le narrateur est l'oncle Pennybags), on comprend que la rentabilité du Monopoly tient à plusieurs facteurs. En premier lieu, à son caractère international : commercialisé en 15 langues et dans 33 pays, plus de 100 millions de jeux ont été vendus dans le monde entier. L'éditeur fabrique chaque année 100 millions de maisons et d'hôtels et imprime pour plus 50 milliards de dollars de monnaie. De nombreuses versions locales, nationales et internationales, voire de luxe ${ }^{36}$, sont également éditées annuellement.

En 1974, un jeu appelé Anti-Monopoly (figure 31) fait l'objet d'une action en justice par Parker Brothers pour contrefaçon, en raison du terme "Monopoly " présent dans le titre. La décision de justice rendue en 1977 donne gain de cause au plaignant et des milliers d'exemplaires de l'Anti-Monopoly sont détruits sur ordre du tribunal. L'inventeur, Ralph Anspach, commercialise alors son jeu sous le nom de «ANTI... * (L'astérisque dans le titre renvoie à un personnage en train de dire "Chut »), mais le sous-titre reste le même : «Bust the Trust " $^{37}$. En 1982, la décision est annulée en appel et l'Anti-Monopoly retrouve son nom. Le verdict devient un cas d'école dans l'industrie et incite les entreprises à protéger rapidement les noms de leurs jeux : le Scrabble devient alors la marque "Scrabble ${ }^{\circledast}$. Ralph Anspach continuera de vendre son jeu dans le monde entier, et publiera par ailleurs un ouvrage sur «la véritable histoire » du Monopoly (Anspach, 1998) basé en grande partie sur la procédure judiciaire avec Parker Brothers. Son livre raconte entre autres que Parker Bros. connaissait - et a pour partie caché - les véritables origines du Monopoly. L'auteur a retrouvé Dan Layman qui, après avoir joué à une version du Monopoly de 1926, en avait produit une version similaire à Indianapolis ${ }^{38}$ sous le nom de Finance ${ }^{39}$. Si son histoire et ses origines restent toujours débattues, le Monopoly n'en demeure pas moins le jeu propriétaire le plus populaire au monde. 


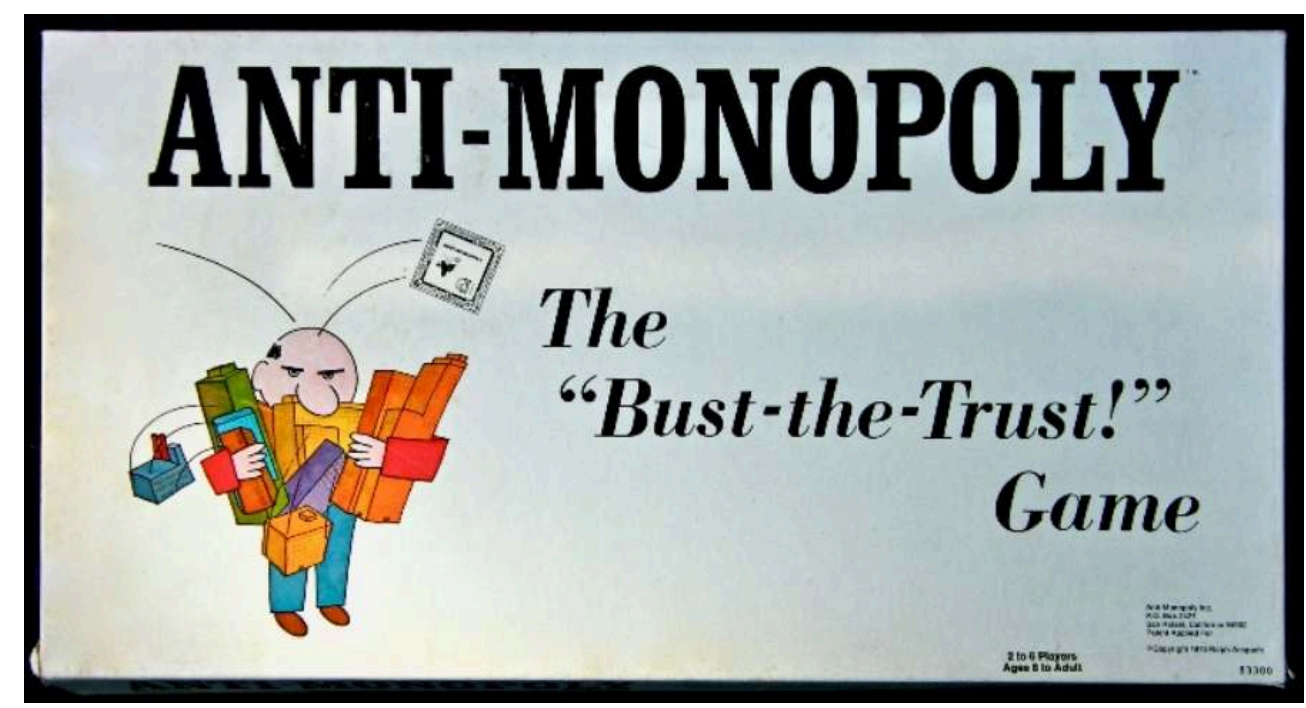

\section{De la reprise à la guerre}

Malgré les difficultés économiques liées à la Grande Dépression, la plupart des entreprises du jeu de société se sont maintenues et les années 1936 et 1937 voient un développement du secteur qui se traduit par des boîtes de jeu plus solides contenant un nombre croissant de pièces. Milton Bradley, présent dans le domaine du matériel scolaire, présente un nouveau jeu avec pour thème la salle de classe dans le jeu Go to the Head of the Class $^{40}$, un titre éducatif et divertissant à base de questions-réponses. Pendant que les États-Unis surveillent de près une Europe qui s'apprête à entrer en guerre, de nouvelles entreprises voient le jour, telles qu'Alderman-Fairchild, CadacoEllis, Einson-Freeman, Pressman, Rosebud, Russell, Stoll \& Edwards, Whitman et Wilder. Le fabricant de jouet Transogram opère une transition vers le jeu de société, tout comme la société Sam'l Gabriel Sons \& Co qui vendait initialement divers produits.

L'entrée des États-Unis dans le nouveau conflit mondial oblige le pays à orienter une nouvelle fois le secteur industriel vers un effort de guerre. L'utilisation des métaux est limitée et de nombreuses entreprises sont contraintes de remplacer les pièces par d'autres matériaux, à l'image des jeux Conflict ${ }^{41}$ et Around the World ${ }^{42}$ de Parker Brothers. Des éditeurs tels que Wolverine, réputé pour ses pièces de jeux en métal, sont particulièrement gênés. Si les thèmes du conflit et du patriotisme deviennent plus populaires encore, le contexte de la guerre limite la production de jeux. En 1941, Milton Bradley réduit son offre de titres de 410 à $150 .{ }^{43}$

En dépit des difficultés économiques, les entreprises continuent à produire des jeux qui, comme les films, offrent un divertissement peu coûteux face aux restrictions de la guerre. Pour certaines structures, parmi les plus petites, l'entrée dans le conflit mondial marque un terme. Les plus importants éditeurs se maintiennent et certains prospèrent à l'image de M.B. qui produit deux nouveaux titres : Game of States ${ }^{44}$ connait en 1940 un succès populaire, et trois ans plus tard, Chutes and Ladders ${ }^{45}$ (figure 32), présenté sur son catalogue comme "le sport d'intérieur le plus célèbre d'Angleterre ». Outre son succès aux États-Unis, ce dernier devient un titre majeur de la culture 
ludique américaine : inspiré du jeu indien Snakes and Ladders ${ }^{46}$, un jeu à vocation morale, les joueurs avancent leur pion sur une échelle (vers le succès) ou le reculent en atterrissant sur la tête d'un serpent ${ }^{47}$. En 1946, le président de Milton Bradley déclare une année record pour sa société qui réduit son endettement d'un demi-million de dollars (Shea 1960). Trois ans plus, M.B. édite Candyland ${ }^{48}$, aujourd'hui encore très populaire chez les enfants. La même année, Parker Bros achète les droits du jeu anglais Cluedo et le distribue sous le nom de Clue (figure 33).

Figure 32 : Chutes and Ladders (Milton Bradley, 1943)

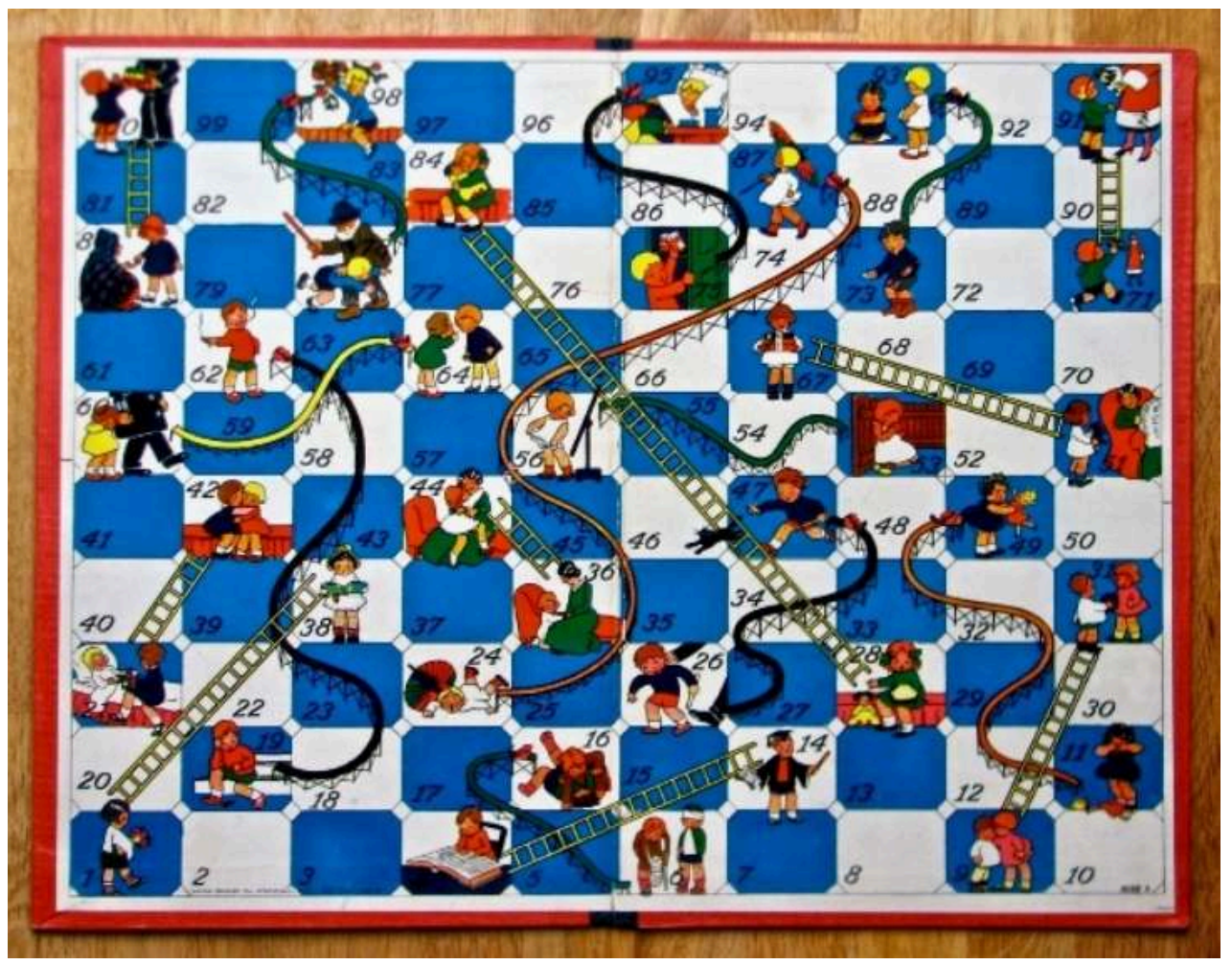


Figure 33 : Clue, The Great Detective Gam (Parker Bros, 1949)

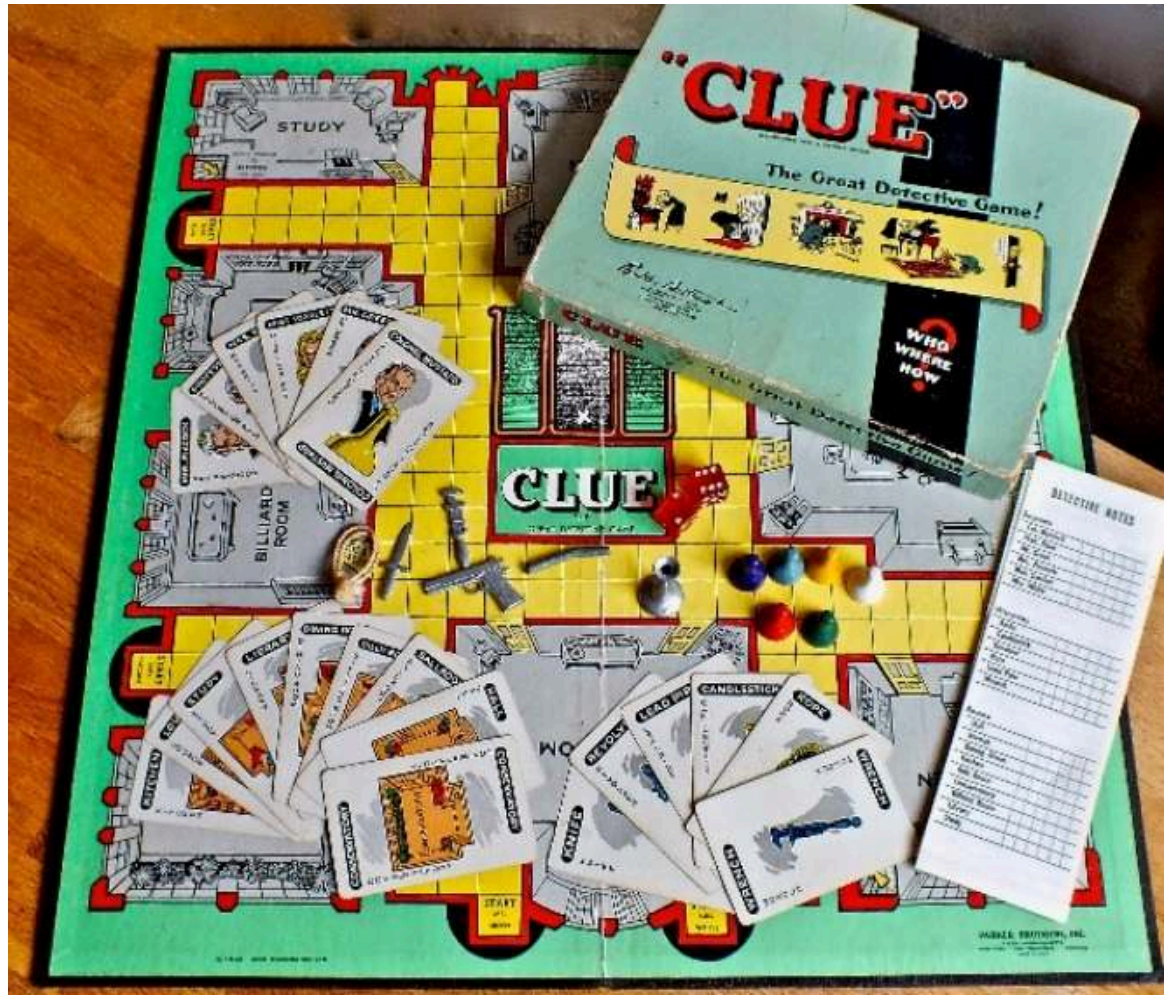

59 La reprise économique de l'après-guerre encourage l'apparition de nouvelles entreprises: National Games, une société de Springfield dans le Massachusetts qui fabriquait des jouets en papier pendant le conflit, produit des jeux de société à partir de 1946. Une autre entreprise de taille modeste commence à fabriquer et à vendre un nouveau jeu sur le principe des mots croisés, sous le nom de Scrabble.

\section{Scrabble, le dernier mot à la mode}

60 Jeu de lettres parmi les plus vendus au monde, le Scrabble est un succès de l'aprèsguerre aux États-Unis au moment où démarre une phase de prospérité économique. Il est d'ailleurs l'un des derniers jeux de société à se diffuser largement sans recourir à la télévision ${ }^{49}$. Commercialisé pour la première fois en 1948, il prend naissance, lorsque, dix ans plus tôt, Alfred Butts décide d'ajouter un plateau à un jeu qu'il avait conçu, Lexico, qui utilisait des tuiles sur lequel étaient imprimées des lettres. Chacune d'entre elles se voit désormais accompagnée d'une valeur numérique et les mots composés par les joueurs sont posés sur un plateau selon le principe des grilles de mots-croisés. La distribution des lettres est calculée à partir de leurs occurrences que l'auteur a comptées sur la première page du New York Times. Observant un engouement pour les mots croisés aux États-Unis, Alfred Butts constate dans le même temps la faible présence de jeux de société de lettres, en dehors du titre Anagrams.

Baptisé dans un premier temps Criss-Cross, puis Criss-Cross Words (figure 34), une demande de brevet est déposée, mais se voit refusée : selon l'inventeur, l'attribution de valeurs numériques à des lettres n'a pas suffi à faire reconnaitre son jeu comme une nouveauté. Comme Charles Darrow, il fabrique et vend alors à son compte ses propres copies (environ 125) jusqu'à ce que d'autres acteurs ne s'intéressent au produit. En 1947 
d'abord, un entrepreneur convaincu de l'intérêt du jeu, James Brunot, prend contact avec Butts. Ils concluent un accord: Brunot fabriquera et commercialisera Criss-Cross Words, sous une forme modifiée et Butts percevra des redevances. Si ce dernier reste crédité au rang des inventeurs, Brunot modifie la conception du plateau, révise les règles, change le nom en Scrabble et le protège par des droits de propriété intellectuelle. Brunot crée la société « Production and Marketing Company » et fabrique le jeu dans le salon de sa maison à Newtown dans le Connecticut, de manière artisanale comme les petits fabricants du siècle précédent. Dès lors, Alfred Butts n'a que peu d'intervention directe dans le développement du jeu (il reste cependant consultant et ami avec Brunot).

Figure 34: Criss Cross Words (Alfred Butts, 1936)

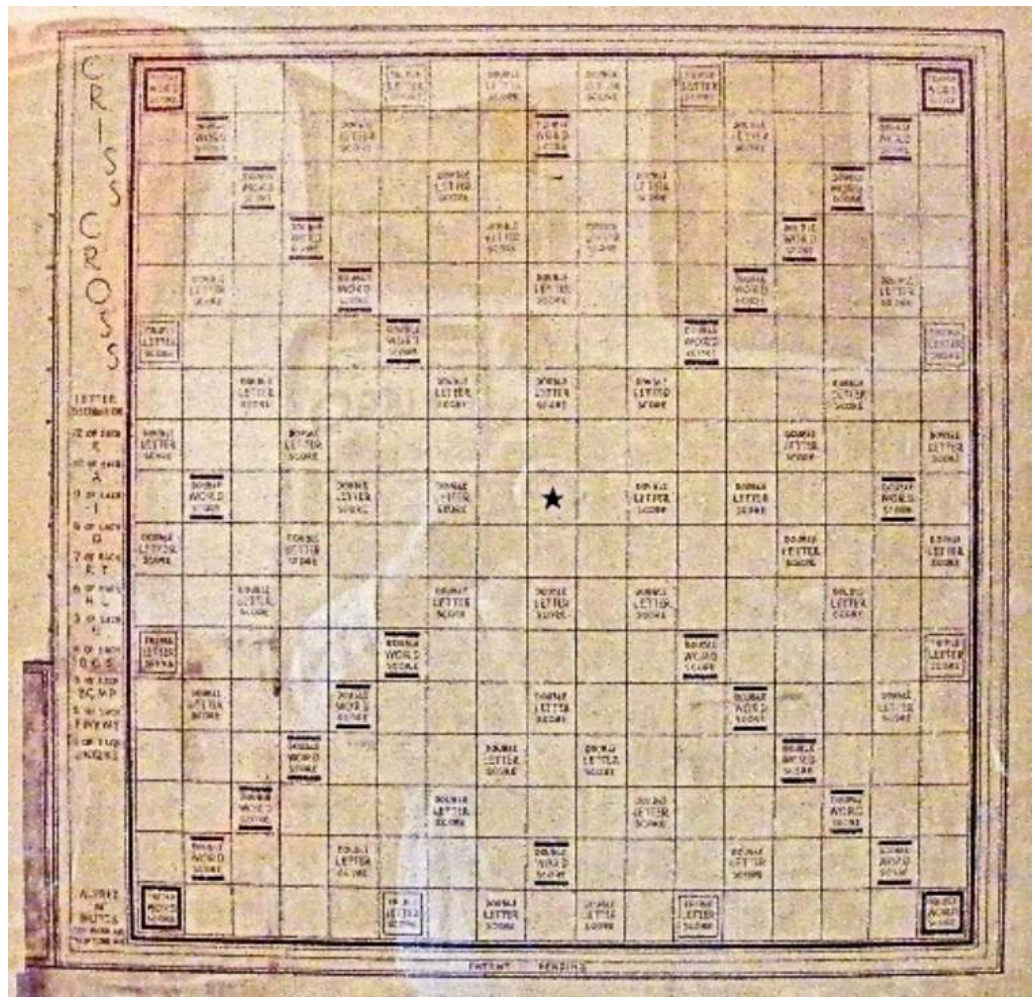

Faisant la fortune de son inventeur et son éditeur, le jeu gagne vite en popularité grâce au bouche-à-oreille et à la publicité papier. En 1949, Brunot fabrique douze à seize Scrabble par jour et sa société connait un déficit de 450 dollars lorsqu'elle achève un premier stock de 2400 boîtes. À partir 1952, la compagnie vend plus de 400 exemplaires par jour. L'année suivante, Brunot ne peut plus répondre à la demande. Selchow \& Righter, la société qui fabrique les plateaux de jeu pour Brunot, rachète alors la licence et prend en charge la fabrication et la commercialisation du jeu. En peu de temps, Selchow \& Righter devient l'un des principaux acteurs de l'industrie américaine du jeu de société.

L'engouement pour le Scrabble fut rapide, et on ne peut que spéculer sur les raisons qui ont présidé à ce succès commercial inattendu. Une première explication veut que le jeu ait été diffusé dans des stations balnéaires à la mode pendant la période de loisirs d'après-guerre et que, lorsque les vacanciers rentraient chez eux, ils cherchaient dans les magasins locaux à se le procurer. Une deuxième explication attribue une partie du 
succès au propriétaire du grand magasin Macy's qui, appréciant personnellement le jeu, s'est assuré de son approvisionnement et de sa promotion dans son établissement.

Les droits sur le Scrabble ont longtemps appartenu à Selchow \& Righter, puis à Coleco qui rachète l'éditeur en 1986. Quelques années plus tard, après la faillite de ce dernier, Hasbro en devient le propriétaire. Le jeu demeure aujourd'hui encore très populaire aux États-Unis et dans de nombreuses régions du monde ${ }^{50}$. Il est traduit dans de nombreuses langues, dont l'hébreu, l'arabe, le japonais et le russe (il existe également une version en braille). Toujours parmi les plus diffusés, plus de 100 millions d'exemplaires du Scrabble se sont vendus dans le monde. Alors que les jeux à succès sont souvent contrefaits, le Scrabble n'a été que peu imité. Il n'existe que deux jeux similaires (outre le jeu original Criss-Cross Words) : Wordy (figure 35) un jeu de 1939 presque identique au Scrabble ${ }^{51}$ édité par Pressman, et Skip-a-Cross, un jeu de CadacoEllis de 1953, version moins chère du Scrabble, avec des tuiles en carton.

Figure 35 : Wordy (Pressman, 1938)

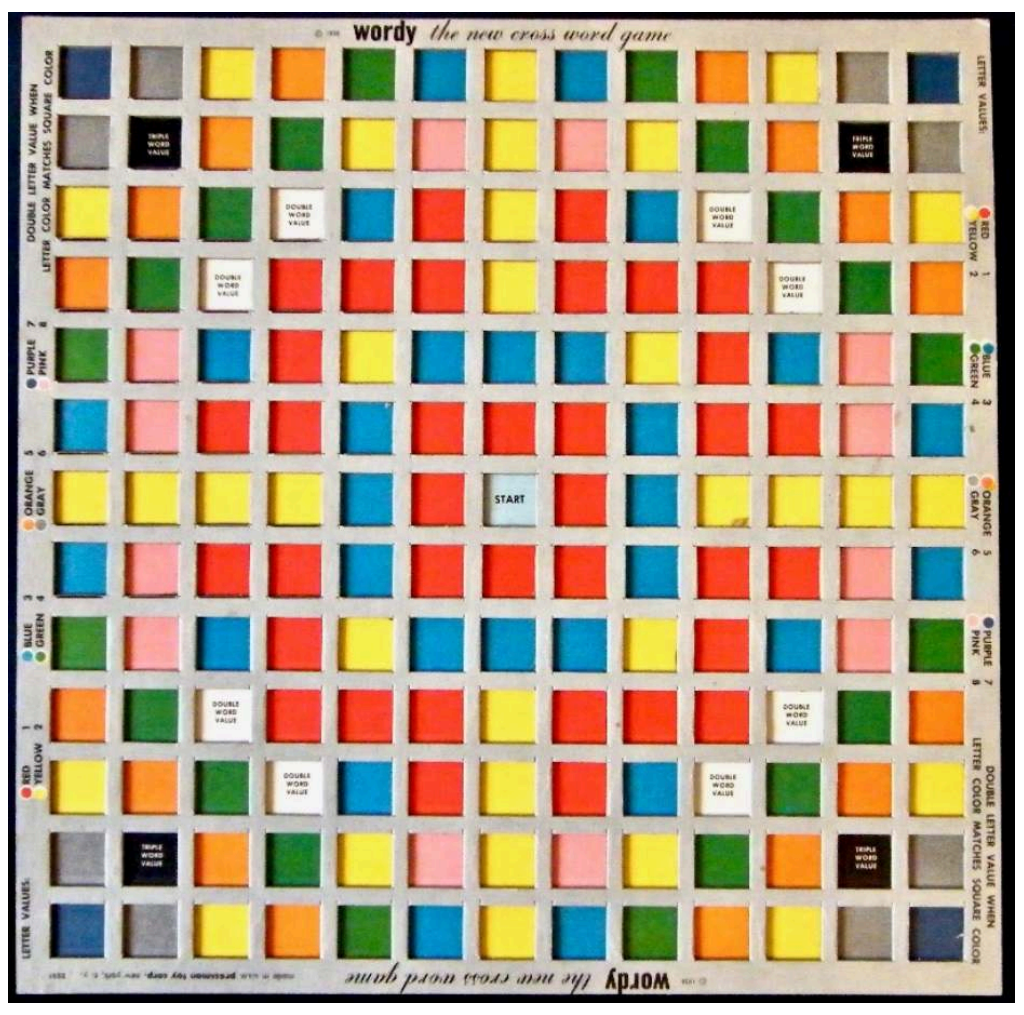

\section{Télévision, licences et distribution : les changements dans l'industrie}

Au lendemain de la Seconde Guerre mondiale, le secteur du jeu de société a été comme d'autres industries profondément bouleversé par la guerre. Cependant, il l'est sans doute plus encore par les ventes massives de téléviseurs qui commencent à la fin des années 1940 et s'accélèrent au début des années 1950. Innovation technique qui introduit dans les foyers une image et une forme d'immédiateté du monde, la télévision change progressivement le secteur du jeu à mesure qu'il transforme les habitudes de nombreux Américains: la vie et les loisirs en famille, mais aussi la consommation 
d'information, de fiction et de jeux. D'un bout à l'autre du pays, ce nouveau média offre une variété de programmes tous interrompus par une multitude de messages publicitaires dans lesquels des personnalités célèbres viennent promouvoir des produits et des loisirs sur un mode intime et personnel. La publicité télévisée devient centrale dans toute activité commerciale et les entreprises du jeu de société comprennent très vite qu'un public, plus large que celui habituellement concerné par la presse écrite, peut être atteint.

Le coût de la publicité télévisée est élevé et seules les grandes entreprises du secteur disposent des capitaux nécessaires. Rapidement, de nombreux petits éditeurs ferment boutique ne pouvant rivaliser sur le plan de la promotion, même si leurs produits pouvaient se révéler aussi bons, voire meilleurs, que ceux de la concurrence. L'absence de réglementation dans les premiers temps permet aux annonceurs de s'adresser directement aux enfants. Faisant appel au sentiment d'appartenance de l'enfant à un groupe social singulier, il s'agit d'encourager la jeunesse à faire acheter aux adultes le jeu du moment et dont beaucoup de parents ne savent que peu de choses. La rhétorique publicitaire de « l'effet de mode $»^{52}$ ( tous les enfants en ont un, vous devriez en avoir un aussi ») se révèle un puissant levier, largement employé. De façon comparable, lorsque les entreprises commencent à éditer des jeux de société basés sur des émissions de télévision, la publicité recourt très souvent à des animateurs ou des célébrités qui, face caméra, témoignent avec conviction de leur engouement pour tel jeu.

Parallèlement à cela, le secteur de la distribution se transforme face au développement des grandes chaînes de magasins de jeux et de jouets à partir des années 1950 . Commandant de grandes quantités d'exemplaires, ces centrales d'achats poussent les prix à la baisse et remplacent progressivement les détaillants indépendants qui, avec un volume plus faible, peuvent difficilement rivaliser. Dans le même temps, les centres commerciaux mettent à disposition de leurs clients un système, très utile, de caisse unique qui permet aux clients de regrouper tous leurs achats. Dans les grandes enseignes du pays, certains jeux et jouets deviennent des « produits d'appel » : promus à grande échelle, achetés en masse et vendus à prix coûtant, ils ont pour principal objectif d'attirer les clients dont les achats compenseront le manque à gagner sur les produits bradés.

68 L'importance que prennent la télévision et la publicité a aussi pour effet de réduire la diversité des titres disponibles. Sans conteste, lorsque les grandes surfaces s'imposent comme les principaux lieux d'achats, elles changent le rapport de force et décident dans une certaine mesure des titres qui seront distribués dans leurs magasins : à moins qu'un jeu ne soit déjà un succès, par voie de média ou par le bouche-à-oreille, une nouvelle création n'est acceptée qu'à la condition que ses ventes soient soutenues par de la publicité télévisée. Quelques grandes sociétés de jeux, Milton Bradley par exemple, arrivent à diffuser certaines nouveautés sans publicité dans des magasins comme Toys-R-Us, mais à la condition que d'autres titres du catalogue fassent l'objet d'une promotion télévisuelle importante. Quand ils ne cessent pas leur activité, les inventeurs indépendants et les petits fabricants qui ne disposent pas de capitaux suffisants pour une campagne publicitaire télévisée se voient contraints de recourir à des moyens de distribution beaucoup plus limités, constituant de fait un secteur de niche. des jeux. Dans un contexte où la présence médiatique d'un jeu devient plus importante 
que sa réputation, il faut désormais réfléchir, d'un point de vue commercial, à ce à quoi ressemblera le jeu dans une page de publicité et quelle personnalité ou personnage sera la mieux à même d'en vanter les mérites. La question est dès lors moins de savoir si un jeu est passionnant à jouer que de s'assurer qu'il le paraisse dans un film promotionnel d'une durée de 15 à 30 secondes. Ce qui se trouve dans la boîte devient moins central que le nom ou la licence qui y est associée.

70 Le phénomène de cession de licence se développe massivement sur cette période : les programmes de télévision s'associent aux éditeurs pour développer un jeu basé sur une émission ou sur un personnage de fiction. On assiste ainsi au début d'une forme d'obsolescence programmée dans l'industrie : un titre est distribué le temps que dure (la popularité de) la série télévisée ou de la célébrité concernée ${ }^{53}$. Au cours des années 1950, de nombreux éditeurs, telles que Milton Bradley, Lowell et Transogram, produisent de plus en plus de jeux liés à des programmes télévisés. Espérant autrefois constituer sur le long terme un catalogue et vendre un titre sur plusieurs décennies, ils fabriquent désormais des objets dont ils savent qu'ils seront passés de mode dans quelques années. Dans le même temps, les petits éditeurs qui ne disposent pas des ressources nécessaires pour cette course aux licences, continuent de vendre et de produire des jeux originaux, mais dont les titres ne sont pas déjà connus et reconnus du public.

71 Ce n'est donc pas une boîte de jeu qui a changé le cours de l'industrie américaine, mais cette « boîte à images » qu'est la télévision. Rien n'a eu un impact aussi profond sur les loisirs. Elle devient un objet central d'attention et éloigne peu à peu les enfants de la pratique des jeux. Tube d'images noires et blanches à ses débuts autour de laquelle se réunissaient les habitants d'un quartier, elle se multiplie dans les foyers et dans les chambres d'enfants à mesure qu'elle devient moins coûteuse, transformant progressivement l'espace familial. Si la télévision a globalement modifié nos habitudes, elle change de façon permanente l'industrie du jeu. Dans cette période, les titres continuent de refléter la société et les événements qui la traversent, mais, à partir des années 1950, les références aux fictions médiatiques se font plus fréquentes à l'image du cowboy Hopalong Cassidy ${ }^{54}$ qui devient un jeu éponyme édité par M.B. Le thème du sport continue d'être populaire tout comme celui des transports, des voyages et de la géographie. Le programme spatial et les préoccupations croissantes en matière de pollution deviennent de nouveaux sujets. Malgré la pléthore de jeux sous licence, quelques titres originaux s'aventurent sur des questions sociales émergentes : le bienêtre, la peine capitale ou encore la criminalité.

Suite au considérable succès du Scrabble, Selchow \& Righter, son éditeur, réduit rapidement le développement d'autres titres et se concentre principalement sur la production sur son jeu phare et de ses dérivés. En 1984 cependant, la société acquiert la licence du Trivial Pursuit auprès de Horn Abbott Inc., un éditeur canadien connu pour le succès de ce titre. Basé sur le principe éprouvé de questions-réponses, mais portant sur six domaines, il devient l'un des jeux les plus vendus au monde. Ce qui distingue le Trivial Pursuit des productions de l'époque est son prix plus élevé que la moyenne dans le secteur de masse, mais aussi la cible de son public: il s'adresse directement à des adultes et non aux familles. La vision des jeux pour adultes était jusqu'ici habituellement attachée à des jeux de stratégie relativement complexes, vendus aux alentours de 12 dollars, et dont les mécaniques étaient très éloignées d'un jeu de société de ce type. Le succès du Trivial Pursuit donne naissance dans l'industrie à une nouvelle 
classification et un nouveau genre : «les jeux conviviaux $»^{55}$ pour adultes. On assiste dès lors à une production surabondante de ce type de jeux, certains se vendant jusqu'à 35 dollars, favorisant le rire, les jeux de mots et les échanges plutôt que la stricte compétition. Permettant ou exigeant que les joueurs jouent en équipes, beaucoup de ces titres mettent l'accent sur l'expérience collective du jeu de société.

\section{La fin d'une époque.}

Depuis la naissance de l'industrie au début $19^{\mathrm{e}}$ siècle, peu d'éditeurs, à l'exception de M.B. et Parker Brothers, ont survécu aux deux guerres mondiales, à la Grande Dépression et au bouleversement du secteur par la télévision. Parmi ceux qui ont vu le jour dans l'entre-deux-guerres, seul Pressman Toy Co. existe toujours en tant qu'entreprise indépendante. Cadaco, qui débute en 1935, devient trente ans plus tard une division de la société Rapid Mounting and Finishing Co.

Les années 1980 et 1990 marquent un tournant dans le secteur : il s'agit d'une période sans précédent de concentration, de rachats et d'acquisitions, qui ne laisse aujourd'hui aux États-Unis qu'une poignée d'entreprises indépendantes. Parker Bros reste un géant du jeu de société jusqu'à son rachat par General Mills en 1968. En 1984, M.B. est racheté par Hasbro, mettant ainsi fin à 124 ans de gestion familiale. Selchow \& Righter, en activité depuis 119 ans, est vendue à Coleco en 1986, après l'absorption de M.B. par Hasbro. Peu de temps après, Coleco fait faillite et se voit racheté par le même éditeur et le nom Selchow \& Righter disparait. Hasbro, désormais propriétaire des plus importantes et historiques sociétés de jeux du pays, ferme l'usine de Parker Brothers à Salem en 1991, mettant ainsi fin à une histoire longue de 108 ans de fabrication de titres dont certains sont classiques: Boggle, Chivalry ${ }^{56}$, Flinch, The Mad Magazine Game, Masterpiece, Mille Bornes ${ }^{57}$, Ouija ${ }^{58}$, Payda ${ }^{59}$, Risk, Sorry, Pente $e^{60}$. Comme Parker Brothers, M.B. occupe une place centrale dans l'histoire et le succès des jeux de société américains. Outre certains jeux télévisés, Milton Bradley a produit de nombreux titres toujours incontournables: Battleship ${ }^{61}$, Concentration, Connect Four ${ }^{62}$, Hangman ${ }^{63}$, Game of India, The Game of Life $e^{64}$, Mousetrap ${ }^{65}$, Operation ${ }^{66}$, Password, Racko, Simon, Stratego, Twister et Yahtzee ${ }^{67}$.

$75 \mathrm{Au}$ cours de leur histoire, Parker Bros, M.B. et Coleco avaient acquis de petites entreprises de sorte qu'aujourd'hui la plupart des catalogues des éditeurs tels que Lakeside, E.S. Lowe, Ideal, Gabriel, Avalon Hill appartiennent tous ou presque à Hasbro. Les principales entreprises qui existaient encore dans les années 1950 - Ideal, Lowell, Transogram, Standard Toykraft - ont disparu. Mattel, bien que très actif dans l'industrie du jouet, a fait plusieurs allers-retours dans le secteur des jeux de société depuis la fermeture de sa division consacrée aux jeux de société à la fin des années 1980. Pressman Toy Company, en activité depuis 1921, est aujourd'hui la plus ancienne société familiale de jeux des États-Unis. Seule une poignée de sociétés historiques, comme Cadaco, Cardinal, Aristoplay et University Games, sont encore actives. Quelques nouvelles sociétés, comme Winning Moves et Endless Games, ont vu le jour pour la période récente.

Comme une grande partie du monde, les États-Unis ont connu de profondes transformations en l'espace de deux siècles. Du temps libre s'est libéré et les offres de loisirs pour le remplir se sont multipliées. L'évolution des structures familiales a modifié la place accordée au jeu de société : la taille des fratries a diminué tandis que 
les grands-parents vivent moins fréquemment qu'avant dans le même foyer que leurs petits-enfants. La place accordée à la télévision et plus récemment aux loisirs numériques s'est accrue dans l'espace domestique. À mesure que les jeux vidéo occupent une place grandissante au sein des loisirs ludiques, les grandes entreprises ont repositionné leurs jeux de cartes ou de plateaux en recourant plus fréquemment à l'électronique et en privilégiant les jeux en trois dimensions. Les productions du secteur de masse renvoient aujourd'hui plus souvent au domaine des jouets pour les enfants qu'à celui des activités de loisir pour les adultes.

La phase de concentration des entreprises dans les années 1980 et 1990 a fait écho à une récession qui a touché l'ensemble des acteurs du secteur. La décennie suivante, Internet redistribue les cartes et commence à transformer les mondes de productions, de ventes et de diffusion du jeu de société. De nouveaux et petits éditeurs, mais aussi des auteurs, commencent à proposer une alternative par une offre de nouveaux jeux de société et de cartes pour adultes, conçus de façon plus traditionnelle. Si le succès de ce monde indépendant reste encore marginal, il parvient parfois à concurrencer le secteur de masse par des produits aux exemplaires souvent moins nombreux, mais de bonne facture.

\section{Conclusion}

Se transmettant d'une génération à l'autre, la pratique des jeux de société reste en grande partie attachée à la sphère familiale. Invitant enfant et parents à partager un moment ensemble, permettant parfois aux premiers de battre leur ainés sur coups de dé, ils sont autant d'occasions pour se divertir, s'affronter sans heurts voire, dans certains cas, s'instruire en famille. Depuis l'expansion vers l'ouest au milieu au $19^{\mathrm{e}}$ siècle jusqu'à nos jours, l'histoire des jeux de société aux États-Unis nous renseigne plus généralement sur l'évolution des structures familiales, de l'enfance et de la jeunesse. À travers l'étude des titres, on peut y voir, comme cet article s'y est efforcé, l'expression d'un continent en plein développement à mesure que le monde change et se rétrécit. À l'époque coloniale, les jeux de société sont issus pour la plupart d'Europe et principalement utilisés pour enseigner des valeurs morales et spirituelles. Au tournant $\mathrm{du} 20^{\mathrm{e}}$ siècle, parallèlement aux mouvements migratoires et aux revendications de liberté politique et de progrès social, les jeux de société deviennent moins révérencieux. Alors que se développe une classe de loisirs, ils deviennent un passetemps singulier et une forme nouvelle et majeure de divertissement. Face à la télévision et aux jeux vidéo, ils perdent cependant de leur importance pour devenir aujourd'hui un divertissement secondaire derrière les écrans. Axé à ses débuts sur l'éducation, l'instruction morale et les valeurs familiales, ce secteur marchand constitué d'entreprises familiales a peu à peu cédé la place à des conglomérats, répondant à des logiques de franchises, aux exigences de la publicité et à celles d'une rentabilité toujours croissante. Les entreprises indépendantes qui constituaient autrefois le cœur de l'industrie américaine du jeu ont presque toutes disparu.

79 Cet article, nous l'espérons, fournira à ses lecteurs quelques repères sur les entreprises et les titres emblématiques de l'industrie du jeu aux États-Unis. Il s'est attaché à explorer les moments et les étapes de son développement et ses évolutions dans le temps. Devant ces rapides changements, notamment ceux intervenus dans les deux dernières décennies (redressements, faillites et rachats), il semble d'autant plus 
important pour la recherche de rassembler les traces de l'histoire de ces objets avant que toutes ces informations ne se perdent ${ }^{68}$. Il reste aujourd'hui encore un important travail à faire d'archivage, de conservation et de préservation de cette histoire américaine du jeu. Les jeux de société sont tout autant acteurs que témoins de l'histoire de nos sociétés, de ses valeurs et de ses évolutions.

\section{BIBLIOGRAPHIE}

ANSPACH R. (1998), The Billion Dollar Monopoly Swindle, Palo Alto, Ralph Anspach

BELL R.C. (1979a), Board and Table Games From Many Civilizations, New York, Dover Publications

BELL R.C. (1979b), The Boardgame Book, Los Angeles, Bookthrift Co.

BELL R.C. (1980), Discovering Old Board Games, Aylesbury, Shire

BOTERMANS J. BURRETT T., VAN DELFT P. \& VAN SPLUNTEREN C. (1989), The World of Games, New York, Jack Botermans

BRANDRETH G. (1981), Favorite Indoor Games, New York, Pantheon

BRANDRETH G. (1892), Cassell's Book of Sports and Pastimes, London, Cassell and Company

COSTELLO M. J. (1991), The Greatest Games of All Time, New York, John Wiley \& Sons

CUDDON J.A. (1980), The International Dictionary of Sports and Games, New York, Schocken Books

CULIN S. (1895), Korean Games With Notes on the Corresponding Games of China and Japan, Philadelphia, University of Pennsylvania Press

CULIN S. (1992 [1907]), Games of the North American Indians, Vol 1: Games of Chance, Vol 2: Games of Skill, Lincoln, Bison Books- University of Nebraska

DENNIS L. (1986), Antique American Games 1840-1940, Elkins Park, Warman Pub Co.

FALKENER E. (1961), Games Ancient and Oriental, and How to Play Them, New York, Nabu Press

FINKEL I. (1996), Ancient Board Games, London, Michael O’Mara

FREDERICK F. (1977), Design and Sell Toys, Games, and Crafts. Radnor, Chilton Book Co.

FREEMAN, J. (1980), The Complete Book of Wargames. New York, Simon \& Schuster

FREEMAN, J. (1975), The PLAYBOY Winner's Guide to Board Games, Chicago, Playboy Press

GIBSON W. (1970), Family Games America Plays, Garden City, Doubleday

GOODFELLOW W. (1991), A Collector's Guide to Games and Puzzles. London, Chartwell House

GRUNFELD F. (1975), Games of the World, New York, Frederic V. Grunfeld

GRUNFELD F. (1869), How to Amuse an Evening Party, New York, Dick \& Fitzgerald

KING C. E. (1978), The Encyclopedia of Toys, New York, Crown Publishers

KRAUS R. (1960), The Family Book of Games, New York, McGraw-Hill Book Company 
LEVY R. C. \& WEINGARTNER, R. O. (1990), Inside Santa's Workshop. New York, Henry Holt \& Co.

LOVE B. (1979a), Great Board Games, London, Michael Joseph

LOVE B. (1979b), Play the Game, London, Michael Joseph

MATTHEWS J. (1994), Toys Go To War, Missoula, Bookworld Press

MCCLINTON K. M. (1970), Antiques of American Childhood, New York, Bramhall House

MCCONVILLE R. (1974), The History of Boardgames, Palo Alto, Creative Pubns

MURRAY H.(1952), A History of Board Games Other Than Chess, New York, Oxford University Press

ORBANES P. (1988), The Monopoly Companion, Boston, Adams Media Corporation

PARLETT D. (1999), The Oxford History of Board Games, Oxford, Oxford University Press

PARTRIDGE E. (1984), A Dictionary of Slang and Unconventional English, London, Taylor \& Francis Routledge

PEEK S. (1987), Gameplan: The Game Inventor's Handbook, White Hall, TBS The Book Service

PENNYCOOK A. (1973), The Indoor Games Book, London, Faber \& Faber

PIGGOTT J. \& SHARP R. (1977), The Book of Games, New York, Galahad Books

POLIZZI R. \& SCHAEFER F. (1991), Spin Again: Boardgames From the Fifties and Sixties, San Francisco, Chronicle Books

PRITCHARD D. (1975), Modern Board Games, London, Inconnu

PRITCHARD D. (1982), Brain Games, Middlesex, Penguin Books

PRITCHARD D. (1994), The Family Book of Games, England, Brockhampton Press

PROVENZO A. B. (1981), Play it Again, Englewood Cliffs, Prentice-Hall

RINKER H. L. (1991), Collector's Guide to Toys, Games, and Puzzles, Radnor, KP Book

SACKSON S. (1900), Everybody's Book of Indoor Games, London, Saxon \& Co.

SACKSON S. (1969), A Gamut of Games, New York, Random House

SCARPONE D. (1995), Board Games, Atglen, Schiffer Books

SCHÄDLER U. (1995), « XII Scripta, Alea, Tabula. New Evidence for the Roman History of

"Backgammon" ", in DE VOOGT A., New Approaches to Board Games Research, Leiden, IIAS, p. 73-98.

SHARP R. \& PIGGOT J. (1977), The Book of Games, London, Artus

SHEA J. Jr. (1960), It's All In The Game, New York, Putnam

SHEA J. Jr. (1973), The Milton Bradley Story, Princeton, Newcomen Society in North America

WASLEY J. (1981), Games for Two, New York and London, Proteus Books

WHITEHILL B. (1992), Games: American Boxed Games and Their Makers, 1822-1992, Radnor, KP Books

WHITEHOUSE, F.R.B. (1971), Table Games of Georgian and Victorian Days, Hertfordshire, Priory Press

WILLIAMS A. D. (1990), Jigsaw Puzzles: An Illustrated History and Price Guide, Radnor, Chilton Book Company

WOOD C.\& GLORIA G. (1940), The Complete Book of Games, Garden City, Doubleday 


\section{NOTES}

1. N.D.T. : Magazine à l'attention des professionnels du jeu et du jouet, publié aux États-Unis entre 1902 et 2010

2. N.D.T. : Salon national du jeu et jouet, inauguré en 1903

3. N.D.T : L'auteur a constitué un fonds de plus de 6000 jeux nord-américains de la fin du $19^{\mathrm{e}}$ siècle à nos jours et sur lequel s'appuie en partie l'article. Une grande partie de cette collection a été acquise en 2007 par le Centre Ludique de Boulogne Billancourt (CLUBB), anciennement appelé Centre National du Jeu (CNJ). Elle fait aujourd'hui partie du Fonds Patrimonial du Jeu de Société (FPJS) à l'université Sorbonne Paris Nord.

4. N.D.T. : Bruce Whitehill est aussi concepteur de jeux. Il a notamment travaillé pour l'éditeur Milton Bradley.

5. Le jeu a également été commercialisé aux États-Unis sous les noms de Home et Pollyanna. Le successeur le plus célèbre du Pachisi a été édité par la société américaine Selchow \& Righter en 1867, sous le nom de Parcheesi, toujours populaire aujourd'hui.

6. N.D.T. : Il se rapproche du jeu connu, en France, sous le nom de Petits chevaux

7. N.D.T.: que l'on peut traduire en français par «maison de la félicité » ou «maison du bonheur"

8. N.D.T. : Le jeu du pape ou du païen

9. N.D.T. : Le siège de la forteresse de Satan par l'armée chrétienne

10. NDT : Le Jeu national de l'aigle américain

11. NDT : Le jeu du garçon coursier

12. NDT : Le garçon désœuvré

13. NDT : "Raggs to Riches ». L'expression désigne en anglais un genre littéraire dans lequel les logiques d'élévation et d'ascension sociale par le travail sont au cœur de la narration.

14. Mais aussi des poupées, des tirelires en fer et en étain, des boîtes à musique, des gants de boxe, des lampes, des baromètres, des poêles de poche, du lierre artificiel et une souris mécanique.

15. N.D.T. : Amiral (1937-1917) connu pour sa victoire lors de la bataille de la baie de Manille pendant la guerre hispano-américaine en 1898.

16. N.D.T : Le garçon de bureau

17. N.D.T. : Le garçon soldat

18. N.D.T. : Chevalerie

19. N.D.T. : À travers le continent

20. N.D.T. : Le jeu du voyage

21. N.D.T : La traversée de l'océan

22. L'auteur souhaite consacrer des recherches plus approfondies aux travaux de Culin et à l'impact qu'ils ont pu avoir sur l'invention des jeux de l'époque. Les jeux de Culin font maintenant partie de la collection du musée de l'université de Pennsylvanie, à Philadelphie.

23. N.D.T : connu en France sous le nom de Dames chinoises

24. La peluche de l'ourson Teddy, «Teddy Bear », a été distribuée par le fabricant de jouet Ideal après que l'un des fondateurs, Morris Michton a obtenu de Roosevelt l'autorisation d'utiliser son nom. La société produira ses premiers jeux de société, 54 ans plus tard, en 1961.

25. N.D.T : Mouvement musical issu du ragtime

26. NDT : Le trot des dindons

27. N.D.T. : De la cabane en rondin à la maison blanche

28. Cette course alors prestigieuse existe depuis 1900, bien avant les célèbres circuits d'Indianapolis et de Daytona

29. N.D.T. : traduction de Duck on a Rock

30. N.D.T : Pirate et voyageur 
31. N.D.T : A la poursuite de Villa

32. N.D.T. : Grand-père rusé

33. N.D.T : Eduquer son père

34. NDT : Le jeu du propriétaire foncier

35. N.D.T. : L'oncle riche Pennybags, littéralement « sac de monnaie »

36. La société Dunhill produira un Monopoly dont les pièces de jeu sont en or massif pour une valeur de 25000 dollars. Neiman-Marcus (chaine de vêtements) fabriquera des exemplaires du jeu avec des pièces et un plateau en chocolat massif, vendus 600 dollars. Dans son catalogue de Noël 1989, une galerie new-yorkaise présente une toile cirée Monopoly, supposément fabriquée par Darrow dans sa propre maison. Le prix demandé est de 50000 dollars. En 1991, le fabricant de monnaie, Franklin Mint, vend autour de 500 dollars une édition «prestige » du Monopoly dans une boîte en bois avec tiroirs. Les pions sont fabriqués en étain massif et embellis avec de l'or 24 carats. Les maisons et les hôtels sont en métal.

37. N.D.T. : Fais sauter le Monopole

38. Une lettre, publiée le 21 février 1936, en atteste

39. N.D.T : en 1932, soit 3 ans avant la version de Parker Bros.

40. N.D.T : Prends la tête de la classe

41. N.D.T : Conflit

42. N.D.T. : Autour du monde

43. La même année est déposé le numéro de brevet américain pour les Dames Chinoises, dérivé du jeu américain Halma.

44. N.D.T. : Le jeu des États

45. N.D.T. : Chutes et échelles

46. N.D.T : Echelles et serpents. C'est sous ce titre que le jeu a été le plus souvent diffusé en France.

47. Selon Eric Partridge (1984, p. 37), l'expression « retour à la case départ » vient de ce jeu dans lequel un lancer de dés malchanceux peut renvoyer un joueur au début.

48. N.D.T. : Le pays des bonbons

49. Quelques jeux continueront cependant de connaitre des succès mondiaux sans s'associer dès leur sortie à la publicité télévisée. Le Mastermind par exemple ou encore le Trivial Pursuit.

50. Le gouvernement thailandais fit la promotion du Scrabble estimant qu'il encourageait l'utilisation de l'anglais, jugé important pour le commerce international.

51. Dans ce jeu, les lettres étaient associées à une couleur et chacune d'entre elles représentait une valeur en points.

52. N.D.T. : Traduction de «bandwagon "

53. Quelques exceptions sont notables, notamment certaines adaptations de jeux télévisés, de type questions-réponses, qui ont continué à être diffusées et à se vendre après la disparation des programmes.

54. N.D.T.: Créé en 1904 par Clarence E. Mulford, ce personnage de fiction a été l'objet de nombreuses adaptations en séries télévisées, films et bandes dessinées.

55. N.D.T : « Party Games », que l'on traduit aussi parfois en français jeux d'ambiance.

56. Ce jeu, présenté comme le «préféré » de George Parker, devient ensuite Camelot.

57. Basé sur le titre Touring qui a inspiré la version française d'Edmond Dujardin acquis par Parker Bros

58. Un jeu de divination des années 1890 acquis par l'éditeur en 1966.

59. N.D.T : édité en France sous le nom de La bonne Paye

60. Ce jeu de plateau est une variante des jeux traditionnels d'alignement comme le Go, le NinukiRenju et le Go-Moku. Introduit en Europe vers 1885, il est connu sous le nom de Spoils Five en Angleterre. Le Pente était également pratiqué aux États-Unis sous le nom de Go-Bang, et figurait dans le catalogue McLoughlin de 1887 et dans le catalogue Parker Brothers de 1894. Le Pente a été relancée en 1977 par un éditeur indépendant et racheté par Parker Bros en 1984. 
61. N.D.T : édité en France sous le nom de Touché-Coulé

62. N.D.T : édité en France sous le nom Puissance 4

63. N.D.T : édité en France sous le nom Le Pendu

64. N.D.T : édité en France sous le nom Destins

65. N.D.T : édité en France sous le nom Attrap'Souris

66. D.T : édité en France sous le nom Docteur Maboul

67. Les droits sur ce titre sont acquis lors du rachat de la société E.S. Lowe par M.B.

68. L'auteur continue ce travail d'archivage des données sur les éditeurs de jeux et leurs produits. Ses recherches actuelles portent sur les travaux de Stewart Culin, leur réception auprès du public et leur impact sur le secteur marchand. L'auteur a également entrepris des recherches sur l'histoire des «jeux de sauts» telles que les Dames Chinoises, Hoppity, Telka, Eckha et Halma, ce dernier étant le seul titre du $19^{\mathrm{e}}$ siècle inventé aux États-Unis et encore joué dans le monde entier.

\section{RÉSUMÉS}

Peu de choses ont été écrites aux États-Unis sur les jeux de société américains et la façon dont ils reflètent, sur une période brève de près de 140 ans, l'évolution de la culture dans laquelle ils ont été conçus. À partir de données issues d'ouvrages et d'articles et, plus encore, en étudiant les produits eux-mêmes, l'auteur a mené un important travail de documentation dans ce domaine ainsi qu'une recherche inédite sur l'histoire des éditeurs. L'objectif de cet article est d'analyser la naissance et la croissance de l'industrie du jeu de société aux États-Unis en portant un regard sur les titres et les évolutions qui ont structuré le secteur, mais aussi sur le contexte culturel dans lequel ils se sont diffusés. Bien que les premiers titres commerciaux aux États-Unis se développent dans une industrie encore balbutiante au regard de la situation européenne, le secteur américain du jeu est une réplique en miniature des transformations que connait ce jeune pays, depuis son essor industriel au milieu du $19^{\mathrm{e}}$ siècle jusqu'au développement d'une Amérique constituée de multinationales aux prises avec des logiques de fusion et de concentration au tournant du nouveau millénaire.

Little has been written in the United States about American boardgames and the way they reflect the evolution of the culture in which they were created during the short 140-year period. The author has attempted to pull together information culled from books and articles covering a broader prospectus, while engaging in original research of game company histories and, more importantly, documenting the products themselves. The purpose of this article is to examine the growth and development of the game industry within the United States, with a look at the products and the trends that defined the industry, and the culture in which they flourished. Though the commercial development of board games in the United States is, by European standards, an industry still in its infancy, American games form a capsule history of the experiences of a young country, from the industrial development of the mid-1800s to a corporate America tangled in takeovers as it propels itself into a new millennium. 
INDEX

Mots-clés : jeu de société, industries, histoire des pratiques, Etats-Unis d'Amérique

Keywords : board game, industries, history of practices, United States of America

\section{AUTEURS}

\section{BRUCE WHITEHILL}

Collectionneur, chercheur, journaliste et essayiste, Bruce Whitehill est l'auteur de plusieurs ouvrages et articles de références sur le développement des industries du jeu de société aux États-Unis (1992). Il est en charge de l'un des plus importants sites de référencement de jeux anciens et récents : « The Big Game Hunter ». Une présentation de ses travaux, de ses activités professionnelles et de ses recherches est disponible ici : https://thebiggamehunter.com/mainmenu-bar/about/about-bgh). 